\title{
Canarias y la previsible ampliación de su plataforma continental: el difícil equilibrio entre España, Marruecos y Sáhara Occidental.
}

\author{
Canary Islands and the foreseeable expansion of its continental shelf: the difficult \\ balance between Spain, Morocco and Western Sahara ${ }^{1}$.
}

\section{Rafael GARCÍA PÉREZ}

Universidade de Santiago de Compostela

rafael.garcia@usc.es

http://orcid.org/0000-0002-4289-3711

Recibido 23/1/2019. Revisado y aceptado para publicación 11/6/2019

Para citar este artículo: Rafael GARCÍA PÉREZ (2019), "Canarias y la previsible ampliación de su plataforma continental: el difícil equilibrio entre España, Marruecos y Sáhara Occidental" en Revista de Estudios Internacionales Mediterráneos, 26, pp. 117-143.

Para acceder a este artículo: https://doi.org/10.15366/reim2019.26.008

\section{Resumen}

En este artículo se analizan los factores jurídicos, políticos y económicos que condicionan la ampliación de la plataforma continental de las Islas Canarias en su zona meridional. Marruecos ha anunciado su intención de realizar una ampliación semejante que incluiría las aguas del Sahara Occidental, territorio no autónomo pendiente de descolonizar sobre el cual Marruecos no detenta la soberanía. Ambas ampliaciones crearían un área de superposición de difícil delimitación que compromete la explotación de los recursos naturales que allí se encuentran.

Palabras clave: Plataforma Continental / Canarias / España / Marruecos / Sáhara Occidental.

\begin{abstract}
The article analyzes the legal, political and economic factors that condition the expansion of the continental shelf of the Canary Islands in its southern zone. Morocco has announced its intention to carry out a similar expansion that would include the waters of Western Sahara, a nonautonomous territory pending decolonization over which Morocco does not hold sovereignty.

\footnotetext{
${ }^{1}$ El presente estudio forma parte de las actividades del Proyecto de Investigación "España ante los nuevos retos de la seguridad marítima: Instrumentos y estrategias en el marco internacional, europeo y peninsular (DER2016-78272-R)", Programa Estatal de I+D+i Orientada a los Retos de la Sociedad (MINECO - Plan Estatal 2017-2019) y Fondo Europeo de Desarrollo Regional (FEDER).
} 
Both expansions would create an overlapping area of difficult delimitation that compromises the exploitation of the natural resources found there.

Key words: Continental Shelf / Canary Islands / Spain / Morocco / Western Sahara.

\section{Introducción}

La delimitación de los espacios marítimos, en particular los relativos a la plataforma continental (PC) y a la Zona Económica Exclusiva (ZEE), constituye todavía hoy una cuestión pendiente de definición en diversas áreas del territorio español. Una de las razones que explican esta ausencia de delimitación se debe a las modificaciones ocurridas en los años setenta del siglo XX, cuando se iniciaron las negociaciones previas a la III Conferencia de Naciones Unidas sobre el Derecho del Mar. La nueva noción de Zona Económica Exclusiva adoptada entonces, con una extensión de hasta 200 millas náuticas (M), al igual que la plataforma continental, dio origen a una revisión generalizada de los límites de los espacios marinos cuya razón de ser transmutó, pasando de ser una franja marítima litoral para garantizar la seguridad de la costa a convertirse en una superficie mucho más extensa, sujeta en diferentes grados a la soberanía y jurisdicción de los Estados costeros, y susceptible de ser utilizada en la explotación de los recursos naturales. Todo ello hizo mucho más compleja y delicada su delimitación.

La Convención de las Naciones Unidas sobre el Derecho del Mar (CONVEMAR)2, tratado multilateral suscrito en 1982 y en vigor desde 1994, establece cinco espacios jurídicos sobre las aguas y los fondos de los océanos [fig.1]: el más cercano a la costa se denomina Mar Territorial, hasta las $12 \mathrm{M}$ sobre el cual, un país tiene derecho de soberanía sobre el espacio aéreo, el agua, suelo y subsuelo marino. En la franja adyacente (entre 12 y $24 \mathrm{M}$ ) se encuentra la Zona Contigua donde el Estado ribereño no tiene soberanía, pero sí derechos de jurisdicción en materia aduanera, sanitaria, fiscal y migratoria. Entre las 12 y $200 \mathrm{M}$, se encuentra la Zona Económica Exclusiva, sobre la cual un país tiene soberanía para la exploración, explotación, conservación y administración de los recursos naturales vivos o no (minerales y recursos energéticos) en sus aguas, suelo y subsuelo marino. Más allá de este límite, la Plataforma Continental puede ser ampliada en $150 \mathrm{M}$ hasta alcanzar las 350M, y dentro de esta zona el Estado ribereño tiene derechos para explorar y explotar recursos naturales del suelo y subsuelo marino, aunque más allá de las $200 \mathrm{M}$ la explotación queda sometida a pagos que deberán ser realizados a la Autoridad Internacional. Más allá del límite exterior de la PC establecido por el Estado ribereño se extiende la Alta Mar, o aguas internacionales, donde rige la libertad de navegación, de sobrevuelo, de tender cables y tuberías submarinos, de pesca y de investigación científica, pero sus fondos marinos, a los que se denomina La Zona, son Patrimonio Común de la Humanidad (PCH) y se encuentran gestionados por la Autoridad Internacional de los Fondos Marinos (ISA) ${ }^{3}$ desde su creación en 1994.

\footnotetext{
${ }^{2}$ Convención de Naciones Unidas sobre el Derecho del Mar (CONVEMAR), de 10 de diciembre de 1982 (BOE de 14 de febrero de 1997), disponible en www.un.org/depts/los/convention_agreements/texts/unclos/convemar_es.pdf [consulta: 10 de diciembre de 2018].

${ }^{3}$ ISA tiene su sede en Kingston, Jamaica (www.isa.org.jm/en)
} 
Figura 1: Los espacios marinos

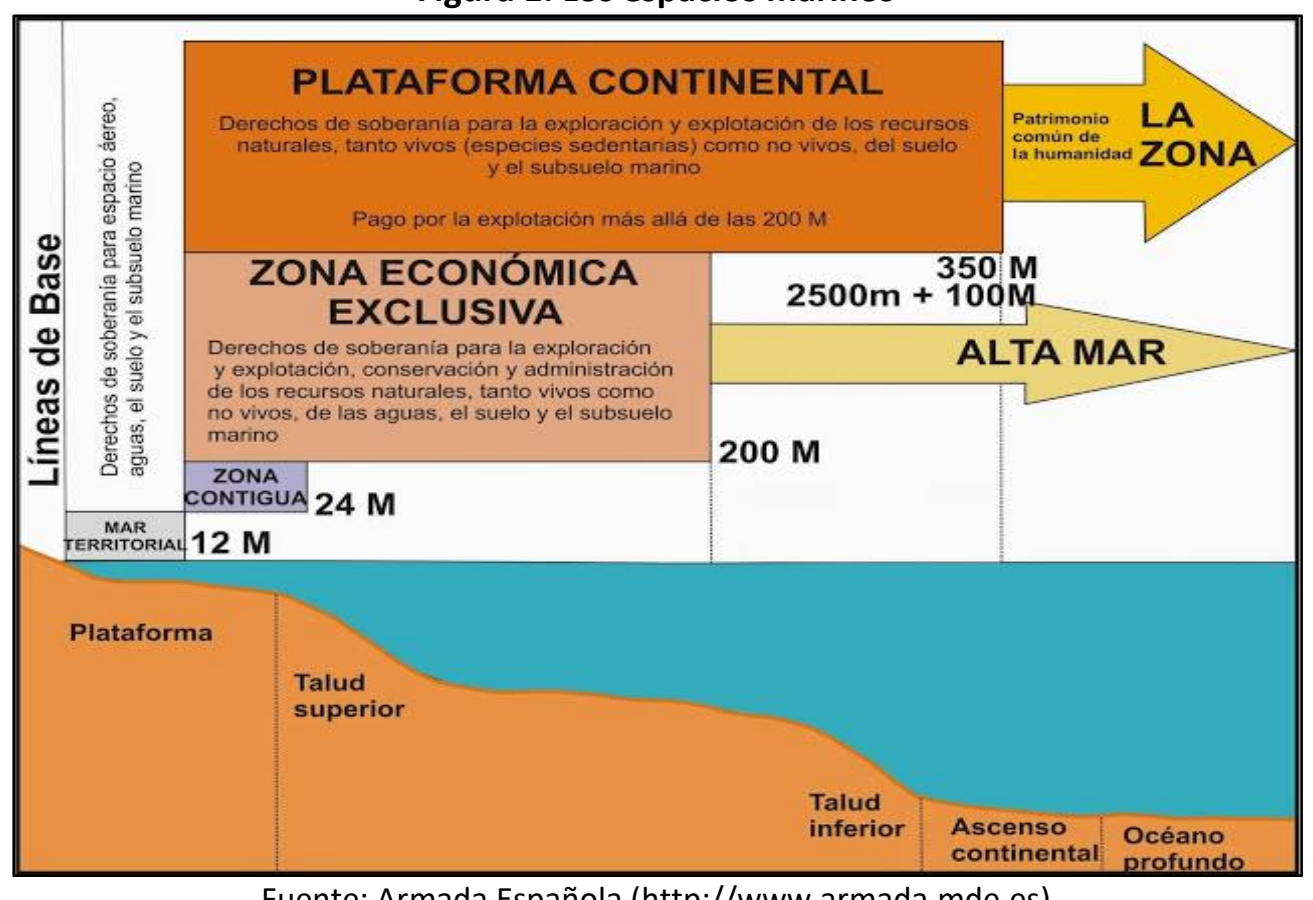

Fuente: Armada Española (http://www.armada.mde.es)

La situación, aún en la actualidad, es que la extensa superficie litoral española tiene pendiente "unas veinte negociaciones de delimitación" con cinco Estados vecinos, tres europeos (Francia, Portugal e Italia) y dos africanos (Marruecos y Argelia), de las cuales "sólo están hechas, como mucho, cuatro de ellas" 4 .

En lo que respecta a las fronteras marítimas con Marruecos sigue planteada la necesidad de delimitar los respectivos espacios marítimos. Asunto sumamente delicado que se entreteje con las ambiciones territoriales marroquíes sobre las plazas de soberanía española ${ }^{5}$ en la costa mediterránea y la pretendida anexión del territorio del Sahara Occidental en la costa atlántica.

A estas cuestiones pendientes se han venido a sumar aquellas derivadas de la posible ampliación de la plataforma continental más allá de las $200 \mathrm{M}$ y que afectan al área de superposición situada al oeste de las Canarias ${ }^{6}$.

El objeto de este estudio es analizar los factores jurídicos, políticos y económicos que condicionan la previsible ampliación de la plataforma continental al oeste de las Islas Canarias como consecuencia de la ocupación por Marruecos del territorio del Sahara Occidental. A ello se le suma la pretensión marroquí de llevar a cabo, igualmente, la ampliación de su propia PC que incluiría, según ha anunciado el gobierno de Rabat, las aguas correspondientes al Sahara Occidental. Asociada de forma directa a este proceso se encuentra la posible explotación de minería submarina en un yacimiento situado en los montes submarinos cuya localización se encuentra al

\footnotetext{
${ }^{4}$ Convención de Naciones Unidas sobre el Derecho del Mar (CONVEMAR), de 10 de diciembre de 1982 (BOE de 14 de febrero de 1997), disponible en www.un.org/depts/los/convention_agreements/texts/unclos/convemar_es.pdf [consulta: 10 de diciembre de 2018].

${ }^{5}$ Cabe recordar que Ceuta, Melilla, los peñones de Vélez de la Gomera y Alhucemas y las islas Chafarinas nunca han sido incluidos en la lista de territorios no autónomos de Naciones Unidas, por lo que nunca han tenido consideración de territorios coloniales sino que internacionalmente siempre han sido considerados parte del territorio español. ${ }^{6}$ Vid. infra, figura 4.
} 
sudoeste del archipiélago canario en el área de superposición donde coincidirían, precisamente, las plataformas continentales ampliadas de España, Marruecos y el Sahara Occidental.

Para poder comprender el alcance y repercusión de todos estos elementos en presencia este estudio explica, en primer lugar, el proyecto de ampliación de la plataforma continental al oeste de Canarias presentado por España ante la Comisión de Límites de la Plataforma Continental de NN.UU. en 2014. Seguidamente se analiza la anunciada pretensión marroquí de proceder igualmente con respecto a su propia plataforma continental y las implicaciones que se derivarían en el caso de que en su presentación fueran incluidas las aguas saharauis, como así parece ser su intención. Finalmente se expone la potencial explotación del yacimiento minero hallado en el extremo meridional de la cordillera submarina canaria y las condiciones en que podría llevarse a cabo su explotación aun en el caso de que el proceso de autodeterminación del Sahara Occidental siguiera sin concluir.

\section{La ampliación de la plataforma continental al oeste del archipiélago canario}

España se ha acogido a la posibilidad de ampliar su plataforma continental siguiendo el procedimiento establecido por la Convención de las Naciones Unidas sobre el Derecho del Mar en su artículo 76. CONVEMAR establece que los Estados ribereños tienen derecho a fijar los límites exteriores de su plataforma continental más allá de las $200 \mathrm{M}$ si proporcionan (dentro de un plazo temporal limitado) la necesaria información científica, geológica y técnica a la Comisión de Límites de la Plataforma Continental de Naciones Unidas. En el caso de ser aprobada dicha extensión, el Estado ribereño pasaría a tener derechos de exploración y explotación de los recursos naturales del suelo y subsuelo marino de la zona ampliada. Esto es, recursos minerales y energéticos del suelo y subsuelo marino y también los recursos marinos vivos, que comprenden las especies animales sedentarias que vivan en constante contacto físico con el fondo del mar o habiten en el subsuelo (art.77).

La Comisión de Límites de la Plataforma Continental (Commission on the Limits of the Continental Shelf, CLCS) ${ }^{7}$, creada en 1997 e integrada por veintiún expertos internacionales, tiene por objeto la evaluación de las propuestas de extensión de la PC y el asesoramiento científico y técnico a los Estados ribereños que elaboran sus correspondientes propuestas de extensión.

España ha presentado ante la CLCS tres propuestas de ampliación de su plataforma continental: una conjunta en el Golfo de Vizcaya $(2006)^{8}$, junto con Francia, Irlanda y Reino Unido, sobre un área de $79.000 \mathrm{~km}^{2}$ que fue aprobada en 20099; y otras dos de forma individual, una frente a Galicia $(2009)^{10}$, sobre un área de $56.000 \mathrm{~km}^{2}$, y la última sobre la región al oeste de Canarias

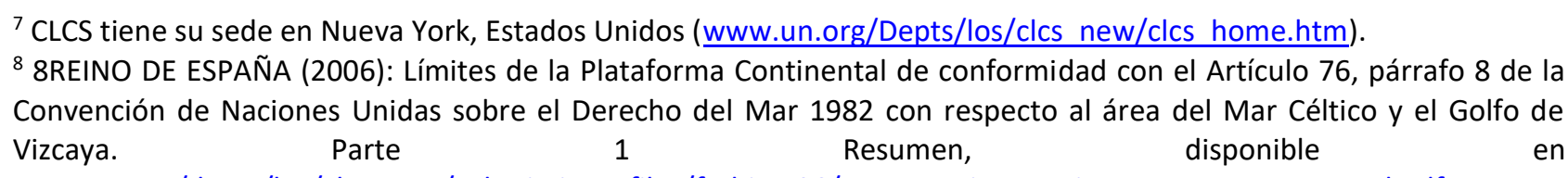
www.un.org/depts/los/clcs new/submissions files/frgbires06/presentacion conjunta resumen espanol.pdf

[consulta: 8 de enero de 2019].

${ }^{9}$ COMISIÓN DE LÍMITES DE LA PLATAFORMA CONTINENTAL (2009): Exposición del Presidente de la Comisión de Límites de la PlataformaContinental sobre la labor de la Comisión (CLCS/62), Nueva York, 20.4.2009. Tema 4, apartados $8 \quad$ a $14, \quad$ disponible en https://documents-ddsny.un.org/doc/UNDOC/GEN/N09/307/61/PDF/N0930761.pdf?OpenElement [consulta: 9 de enero de 2019]. Se encuentran aún pendientes de conclusión las negociaciones entre los cuatro Estados concernidos (España, Francia, Irlanda y Reino Unido), para establecer la delimitación de las respectivas áreas marinas.

10 10REINO DE ESPAÑA (2009): Presentación ante la Comisión de Límites de la Plataforma Continental (Presentación parcial relativa a los límites de la Plataforma Continental de España en el área de Galicia, de conformidad con el artículo 76 y el anexo II de la Convención de las Naciones Unidas sobre el Derecho del Mar). Parte 1 Resumen Ejecutivo,

disponible 
$(2014)^{11}$, con una extensión de $220.000 \mathrm{~km}^{2}$, ambas pendientes aún de examen por parte de la Comisión.

Las Reglas de Procedimiento establecidas por la $\mathrm{CLCS}^{12}$, obligan a los Estados a informar de la ausencia de controversias territoriales de sus propuestas con países vecinos y limítrofes. El Estado interesado debe acreditar ante la Comisión de Límites la ausencia de controversias jurídicas con otros Estados ribereños, así como reconocer explícitamente que la presentación que vaya a realizar no prejuzga en modo alguno las cuestiones relativas a la fijación de límites entre Estados ${ }^{13}$.

También es necesario destacar que las decisiones aprobadas por la Comisión de Límites tienen el carácter de una mera recomendación que se ofrece al Estado ribereño sobre cuestiones precisas relacionadas con la determinación del límite exterior de la plataforma continental ampliada. Pero la fijación definitiva de ese límite corresponde al propio Estado, sobre la base de las recomendaciones emitidas por la Comisión (art. 76.8 CONVEMAR). En ningún caso, estas recomendaciones pueden prejuzgar la delimitación del límite externo de la PC entre Estados con costas adyacentes o situadas frente a frente (art. 76.10 CONVEMAR). En tales casos, el procedimiento para la delimitación tanto de la PC como de la ZEE establece que debe realizarse por acuerdo entre las partes, de conformidad con el Derecho Internacional, con el objetivo de llegar a un acuerdo equitativo entre las partes ${ }^{14}$. En consecuencia, el acuerdo sobre los límites definitivos de la PC entre Estados, sólo podrá ser resuelto con posterioridad a la emisión de las recomendaciones por parte de la Comisión de Límites y será determinada por los Estados concernidos de común acuerdo a través de una negociación bilateral ${ }^{15}$.

Cabe destacar que tanto Portugal como España han indicado de forma expresa la ausencia de controversias territoriales en el área afectada por la posible ampliación de sus respectivas plataformas continentales, así como su intención de realizar la delimitación de las respectivas áreas conforme a las exigencias del Derecho Internacional ${ }^{16}$.

http://www.un.org/Depts/los/clcs new/submissions files/esp47 09/esp 2009 summary esp.pdf [consulta: 9 de enero de 2019].

11 REINO DE ESPAÑA (2014): Presentación parcial de datos e información sobre los límites de la Plataforma Continental de España al Oeste de las Islas Canarias. Parte I Resumen Ejecutivo, disponible en www.un.org/depts/los/clcs new/submissions files/esp77 14/esp 2014 es.pdf [consulta: 9 de enero de 2019].

12 COMISIÓN DE LÍMITES DE LA PLATAFORMA CONTINENTAL (2008a): Reglamento de la Comisión de Límites de la Plataforma Continental (CLCS/40/Rev.1) Nueva York, 17.4.2008, disponible en https://undocs.org/es/CLCS/40/Rev.1 [consulta: 8 de enero de 2019].

${ }^{13}$ CONVEMAR: Art. 83; REGLAMENTO DE LA COMISIÓN DE LÍMITES DE LA PLATAFORMA CONTINENTAL

(CLCS/40/Rev.1, 18.4.2008), Artículo 46.1 y Anexo I.

${ }^{14}$ CONVEMAR: “Artículo 83.-Delimitación de la plataforma continental entre Estados con costas adyacentes o situadas frente a frente. 1. La delimitación de la plataforma continental entre Estados con costas adyacentes o situadas frente a frente se efectuará por acuerdo entre ellos sobre la base del derecho internacional, a que se hace referencia en el artículo 38 del Estatuto de la Corte Internacional de Justicia, a fin de llegar a una solución equitativa".

${ }^{15}$ GUTIÉRREZ CASTILLO, Víctor L. (2017): “La delimitación de los espacios marinos”, en MARIÑO MÉNDEZ, Fernando M. (dir.), Instrumentos y regímenes de cooperación internacional, Madrid, Trotta, pp.383-403.

${ }^{16}$ Nota verbal ONU/2009/134 de 28 de mayo de 2009 y Nota Verbal n³53AV/ot de 28 de mayo de 2009 presentadas respectivamente por las Misiones Permanentes de Portugal y España ante las NN.UU., disponibles en http://www.un.org/Depts/los/clcs new/submissions files/esp47 09/prt re esp2009.pdf http://www.un.org/Depts/los/clcs new/submissions files/prt44 09/esp re prt2009.pdf, respectivamente [consulta: 12 de enero de 2019] 
La exposición ante la CLCS sobre la presentación parcial con respecto a la zona al oeste de las Islas Canarias tuvo lugar el 26 de agosto de $2015^{17}$ teniendo como fundamento científico las evidencias obtenidas durante las seis campañas ${ }^{18}$ de investigación oceanográfica realizadas entre 2010 y 2014, sumadas a los datos batimétricos obtenidos con anterioridad en las cuatro campañas realizadas por el Ministerio de Defensa sobre la ZEE ${ }^{19}$.

En su presentación ${ }^{20}$ España señaló la ausencia de controversias en el área de la plataforma continental al oeste de las Canarias, destacando que la presentación no prejuzga ni perjudica la fijación del límite exterior de la plataforma resultante de la presentación realizada por Portugal ${ }^{21}$ ni de los derechos que puedan ser reclamados en su día por "terceros", omitiendo mencionar de este modo al Sahara Occidental.

Marruecos no se opone al examen de la presentación española por parte de la CLCS, pero manifiesta una serie de reservas a través de dos notas verbales ${ }^{22}$. En la primera de ellas $^{23}$ se recuerda la ausencia de una delimitación de los espacios marinos entre los dos países, reafirmando su tradicional postura de aplicación del principio de equidad frente al de equidistancia. A continuación se critica la utilización de las líneas de base rectas establecidas por la Ley de aguas canarias de $2010^{24}$ [fig. 2, en rojo] como punto de referencia para medir el límite exterior de la plataforma continental ampliada. España respondió ${ }^{25}$ a esta objeción recordando que las líneas de base empleadas en la presentación son las definidas por el RD 2510/1977 de 5 de agosto [fig. 2, en blanco], como se reflejaba de forma expresa en la presentación.

\footnotetext{
17 Previamente, la presentación fue hecha el 17 de diciembre de 2014. La exposición fue realizada por la jefa de la delegación española, Ana María Salomón Pérez, Presidenta de la Comisión Internacional de Límites con Francia y Portugal del Ministerio de Asuntos Exteriores y de Cooperación (MAEC); José Martín y Pérez de Nanclares, Jefe de la Asesoría Jurídica Internacional del MAEC; y Luis Somoza Losada, Coordinador Científico del Instituto Geológico y Minero de España (IGME). COMISIÓN DE LÍMITES DE LA PLATAFORMA CONTINENTAL (2015): Progresos en la labor de la Comisión de Límites de la Plataforma Continental, 1 de octubre de 2015 (CLCS/90), pp.15-16, disponible en https://documents-dds-ny.un.org/doc/UNDOC/GEN/N15/297/42/PDF/N1529742.pdf?OpenElement [consulta: 9 de enero de 2019]; MARTíN Y PÉREZ DE NANCLARES, José (2016): “Plataforma continental ampliada al oeste delas Islas Canarias: presentación española ante la comisión de límites de la plataforma continental”, Revista Española de Derecho Internacional, Vol. 68, no 1, pp. 219-226.

18 GAROE-2010, DRAGO-2011, GAIRE-2011, ZEEE-2011, AMULEY-ZEEE-2012 Y MAEC-SUBVENT-1 2013, coordinadas por el IGME, REINO DE ESPAÑA (2014): Op, cit.

19 Plan de Investigación Científica de la ZEE, campañas ZEEE-1999, ZEEE-2000, ZEEE-2011 Y ZEEE-2012. Memoria del Instituto Hidrográfico de la Marina. Año 2012, Madrid, Ministerio de Defensa, 2013, p.40, disponible en https://publicaciones.defensa.gob.es/media/downloadable/files/links/P/D/PDF430.pdf [consulta: 10 de enero de 2019].

${ }^{20}$ REINO DE ESPAÑA (2014), p.10.

21 PORTUGUESE REPUBLIC (2009): Continental Shelf of Portugal. ExecutiveSummary. Estrutura de Missão para a $\begin{array}{lllll}\text { Extensão da Plataforma } & \text { Continental disponible }\end{array}$
} www.un.org/depts/los/clcs new/submissions files/prt44 09/prt2009executivesummary.pdf [consulta: 8 de enero de 2019].

${ }^{22}$ Ya antes, en el momento en que España manifestó por vez primera ante la CLCS su intención de extender la plataforma continental al oeste de Canarias (11.5.2009), Marruecos había remitido una nota verbal reservándose el derecho a estudiar el proyecto español y recordando la jurisprudencia internacional (Art.83.1 CONVEMAR) que impide la delimitación unilateral de los espacios marinos. Nota Verbal no NV/187/09 de la Misión Permanente de Marruecos ante las Naciones Unidas, de 16 de mayo de 2009, disponible en http://www.un.org/Depts/los/clcs new/submissions files/esp47 09/mor re esp2009.pdf [consulta: 12 de enero de 2019].

${ }^{23}$ 23Nota Verbal no NV/ATL/N/ 114/2015 de la Misión Permanente de Marruecos ante las Naciones Unidas, de 10 de marzo de 2015, disponible en http://www.un.org/Depts/los/clcs new/submissions files/esp77 14/mor re esp77.pdf [consulta: 12 de enero de 2019].

24 Ley 44/2010, de 30 de diciembre, de aguas canarias (BOE del 31.12.2010), disponible en www.boe.es/buscar/pdf/2010/BOE-A-2010-20140-consolidado.pdf [consulta: 8 de enero de 2019].

${ }^{25}$ Nota Verbal no 076 MP/bcm de la Misión Permanente de España ante las Naciones Unidas, de 22 de abril de 2015, disponible en http://www.un.org/Depts/los/clcs new/submissions files/esp77 14/prt remar esp77 spa.pdf [consulta: 12 de enero de 2019]. 
Figura 2: Líneas de base rectas del archipiélago canario ${ }^{26}$

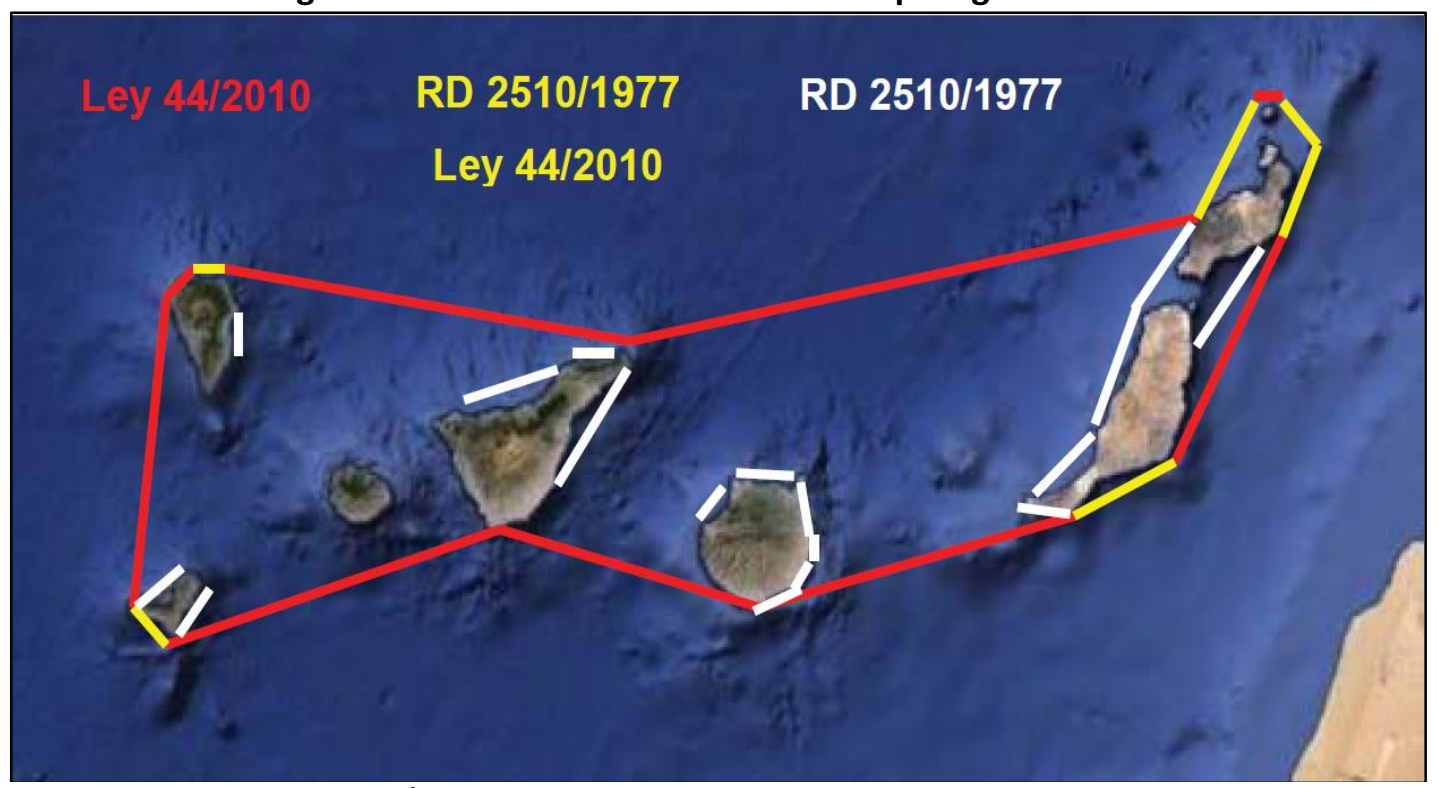

Fuente: GARCÍA QUINTELA, Adolfo (2015): El Ministerio de la Mar, p. 26

En su segunda nota verbal ${ }^{27}$ Marruecos insistía en la falta de delimitación de sus espacios marinos con Portugal, España, Mauritania y Cabo Verde y ofrecía información preliminar sobre su plataforma continental extendida más allá de las $200 \mathrm{M}^{28}$. España no ha respondido a esta nota verbal. En la exposición oral ante la CLCS el Jefe de la Asesoría Jurídica del MAEC manifestó:

"la opinión de su Gobierno de que en esas comunicaciones se resaltaba una posible superposición con una futura presentación relativa a la plataforma continental más allá de las 200 millas marinas medidas desde el territorio del Sáhara Occidental, que era un Territorio No Autónomo que estaba transitando un proceso de descolonización. El Sr. Martín y Pérez de Nanclares afirmó que España estaba dispuesta a negociar una solución equitativa basada en el derecho internacional, tanto con Portugal como con la entidad que tenía [sic] el control soberano de las costas y el territorio del Sáhara Occidental, una vez que se considerara concluido el proceso de descolonización" 29 .

En consecuencia, la posición española no deja lugar a dudas y se pliega escrupulosamente a lo establecido por el Derecho Internacional: el acuerdo sobre los límites definitivos de la PC entre Estados, sólo podrá ser resuelto con posterioridad a la emisión de las recomendaciones por parte

\footnotetext{
${ }^{26}$ El color amarillo corresponde con las líneas de base que coinciden tanto en el RD como en la Ley de 2010. Sobre el particular Vid. ORIHUELA CALATAYUD, Esperanza (2011): “La delimitación de los espacios marinos en los Archipiélagos de Estado. Reflexiones a la luz de la ley 44/2010, de 30 de diciembre, de aguas canarias", Revista Electrónica de Estudios Internacionales, no 21 disponible en www.reei.org/index.php/revista/num21/articulos/delimitacion-espaciosmarinos-archipielagos-estado-reflexiones-luz-ley-442010-30-diciembre-aguas-canarias [consulta: 12 de enero de 2019].

${ }^{27}$ Nota Verbal no NV/ATL/N/ 325/2015 de la Misión Permanente de Marruecos ante las Naciones Unidas, de 29 de julio de 2015, disponible en http://www.un.org/Depts/los/clcs new/submissions files/prt44 09/mar re prt2015.pdf [consulta: 12 de enero de 2019].

${ }^{28}$ ROYAUME DU MAROC (2015): Rapport d'informations sur le Plateau Continental Atlantique du Royaume du Maroc au-delà des 200. Milles Marins $(200 \quad \mathrm{M})$ (Juillet 2015), disponible en http://www.un.org/Depts/los/clcs new/submissions files/preliminary/Mor2015 preliminaryinfo.pdf [consulta: 11 de enero de 2019].

${ }^{29}$ COMISIÓN DE LÍMITES DE LA PLATAFORMA CONTINENTAL (2015): Op. cit., p.16.
} 
de la Comisión de Límites y será determinada por los Estados concernidos de común acuerdo a través de una negociación bilateral ${ }^{30}$. El problema en este caso radica en determinar quién ostenta la soberanía del territorio del Sahara Occidental tras finalizar el proceso de descolonización.

En su presentación ante la CLCS España ha identificado el límite exterior de la plataforma continental extendida más allá de las $200 \mathrm{M}$ sin rebasar las $350 \mathrm{M}$ tomando como punto de medición las líneas de base rectas del archipiélago canario definidas por el RD 2510/1977 [fig. 3].

Figura 3: Límite exterior de la plataforma continental de España más allá de las $200 \mathrm{M}$ en el área al Oeste

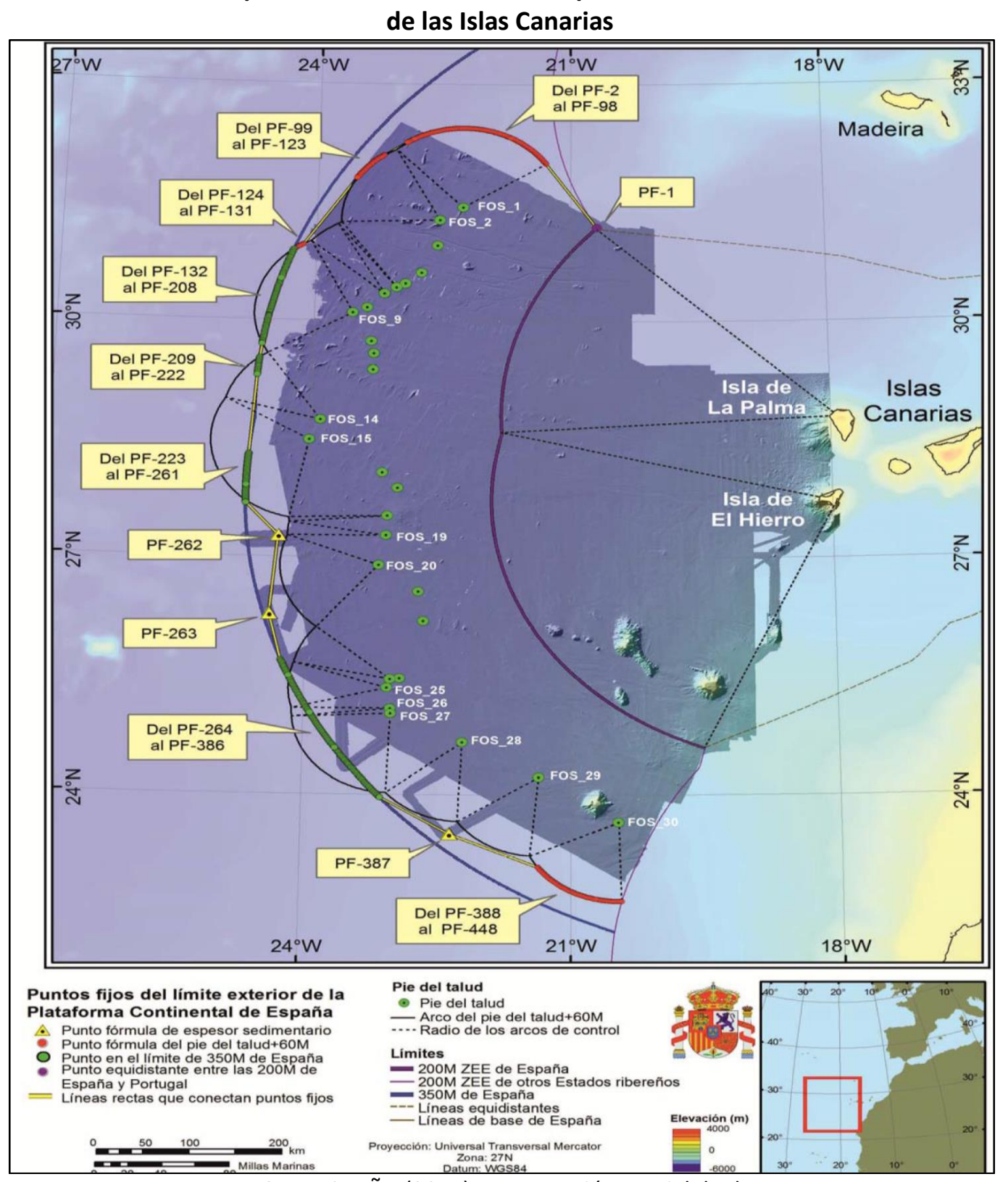

Fuente: REINO DE ESPAÑA (2014): Presentación parcial de datos ..., p.17.

De llevarse a cabo, esta ampliación daría lugar a dos áreas de superposición con las plataformas continentales extendidas de Portugal (al Norte) y Marruecos (al Sur) [fig. 4]. Cada una de estas áreas plantea problemas de delimitación territorial específicas: con Portugal debido a las Islas Salvajes ${ }^{31}$ y con Marruecos debido al proceso de descolonización no consumado del Sahara Occidental ${ }^{32}$.

\footnotetext{
${ }^{30}$ Vid. supra nota 15.

${ }^{31}$ NEVES COELHO, Paulo (2017): “A delimitação dos espaços marítimos de Portugal após a aprovação da extensão da plataforma continental” y GARCíA PÉREZ, Rafael (2017): “La delimitación de los espacios marinos entre España y
} 
Figura 4: Solapamientos entre las zonas de potencial extensión de la plataforma continental más allá de las $200 \mathrm{M}$ de terceros Estados

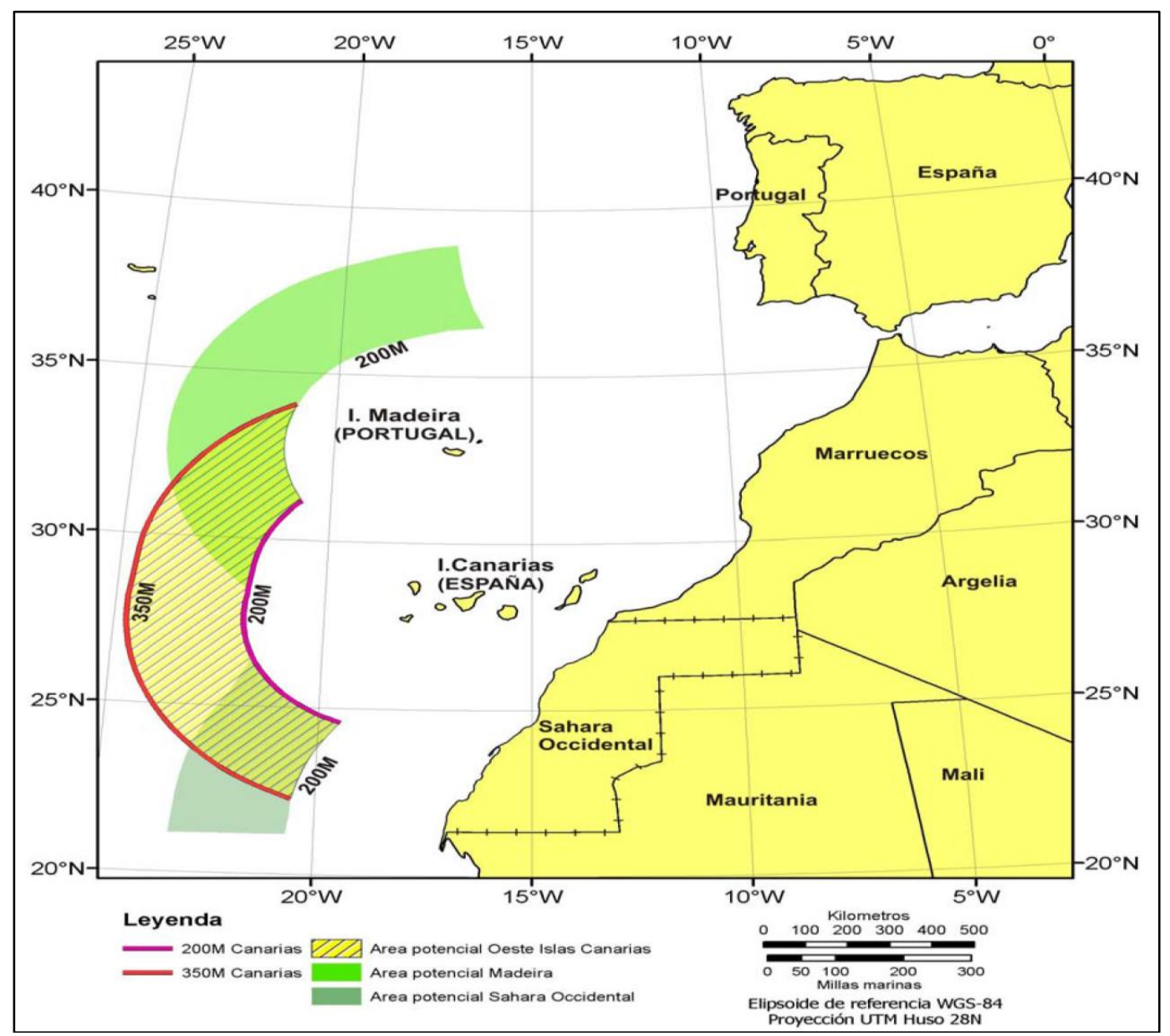

Fuente: REINO DE ESPAÑA (2009): Presentación ante la Comisión de Límites..., p. 27.

En el caso que nos ocupa al existir un área de montes submarinos en la zona meridional correspondiente a la ampliación debe considerarse el artículo 76.6 de la Convención ${ }^{33}$. Al tratarse de cordilleras volcánicas formadas en el fondo del océano en relación con el movimiento de la corteza terrestre sobre puntos calientes ${ }^{34}$, el único criterio aceptado para la determinación de un punto fijo es el de la distancia [fig. 5].

Portugal en caso de ampliarse la plataforma continental más allá de las 200 millas", ambos capítulos en GARCíA PÉREZ, Rafael; NEVES COELHO, Paulo y FERREIRA RODRIGUES, Teresa (coords): A extensão das plataformas continentais: Portugal e Espanha, perspectivas e realidades. Porto, Fronteira do Caos, pp. 85-105 y 107-138, respectivamente.

32 JIMÉNEZ GARCÍA-CARRIAZO, Ángeles (2018): La ampliación de la plataforma continental más allá de las doscientas millas marinas. Especial referencia a España. Madrid, Dykinson, pp.253-268.

${ }^{33}$ CONVEMAR, “Artículo 76.6. No obstante lo dispuesto en el párrafo 5, en las crestas submarinas el límite exterior de la plataforma continental no excederá de 350 millas marinas contadas desde las líneas de base a partir de las cuales se mide la anchura del mar territorial. Este párrafo no se aplica a elevaciones submarinas que sean componentes naturales del margen continental, tales como las mesetas, emersiones, cimas, bancos y espolones de dicho margen". 34 INSTITUTO ESPAÑOL DE OCEANOGRAFÍA (2011): Informe Científico-Técnico de la Campaña Oceanográfica DRAGO 0511. Ampliación de la Plataforma Continental de España al Oeste de las Islas Canarias, Madrid, Instituto Español de Oceanografía, p. 18, disponible en www.repositorio.ieo.es/e-ieo/bitstream/handle/.../Informe\%20DRAG00511.pdf [consulta: 11 de mayo de 2016]. 
Figura 5: Detalle de la zona sur del límite exterior de la plataforma continental de España más allá de las 200 M en el área al Oeste de las Islas Canarias

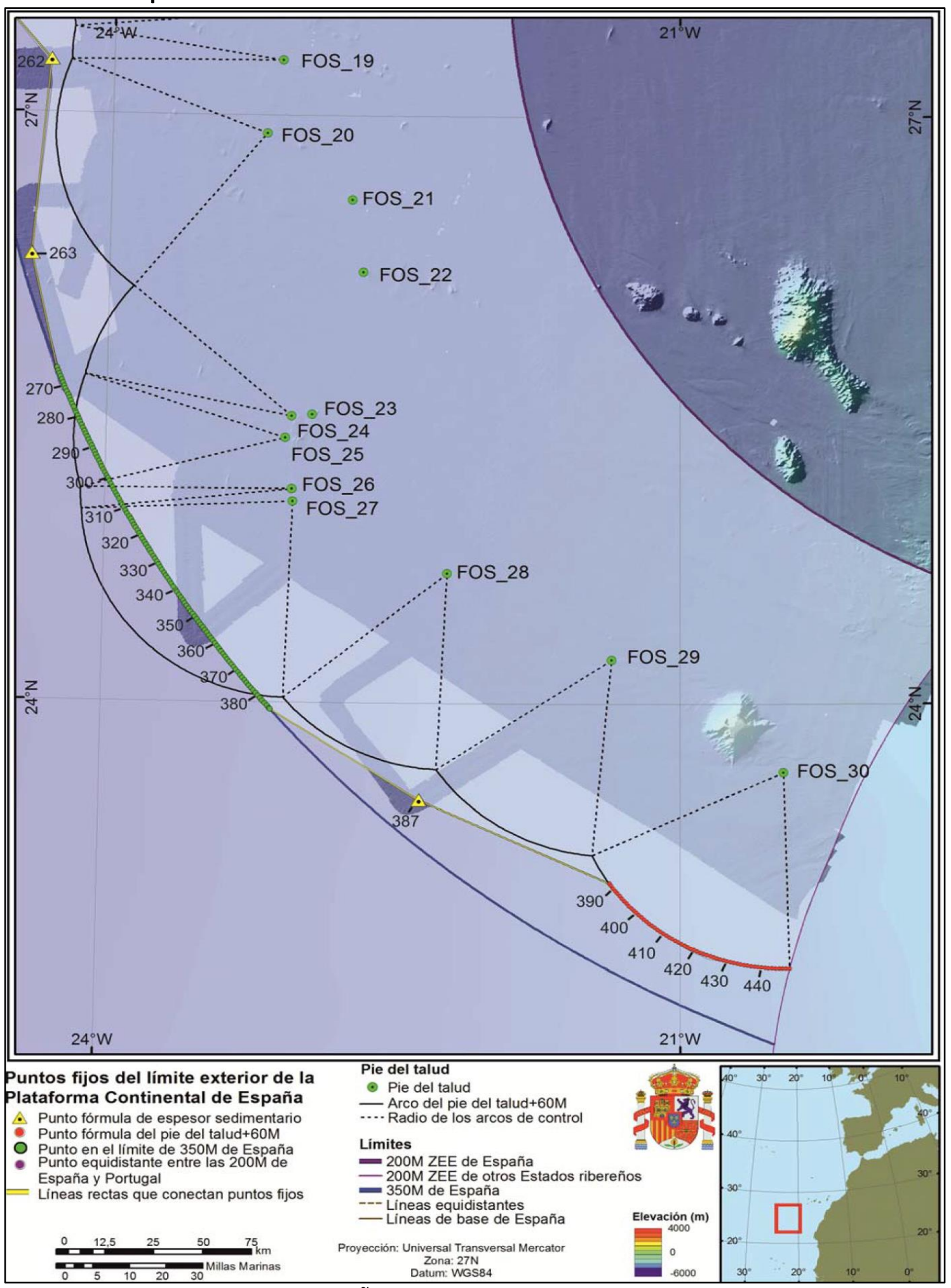

Fuente: REINO DE ESPAÑA (2014): Presentación parcial de datos ..., p.19.

La emisión de las recomendaciones de la Comisión de Límites sobre este caso aún va a tardar mucho tiempo. El estudio de las propuestas se hace por riguroso orden de presentación. España ocupa el puesto 77 y la última recomendación emitida fue la referida al número 32 (marzo de 2017). Pero incluso cuando la CLCS se pronuncie, confiemos que de forma favorable a los intereses de España, estaremos lejos de ver resuelto este asunto dada la pervivencia del resto de factores que inciden sobre el mismo. 


\section{Superposición en la jurisdicción de espacios marinos entre España, Marruecos y Sáhara Occidental}

Existen al menos tres factores que intervienen de modo directo en este caso. El primero de ellos lo constituye la previsible superposición en un área significativa entre la plataforma continental ampliada de las Islas Canarias y la de Marruecos, en el caso de que finalmente realice su presentación como así ha anunciado. El segundo de ellos deriva del hecho de que Marruecos incluya dentro de su presentación las aguas del Sahara Occidental, como parece ser su intención, obviando la condición de territorio no autónomo pendiente de descolonización que formalmente tiene ante las NN.UU. El tercero de los factores se evidenciaría en el caso de producirse la explotación de esa área del fondo y subsuelo marino y, de forma más precisa, en la legitimidad de las autoridades marroquíes para llevarla a cabo al margen de los intereses de la población saharaui. Aunque estos tres factores se manifiesten en la práctica asociados con la delimitación de espacios marinos la razón común de todos ellos deriva de la condición del Sahara Occidental como territorio no autónomo y que, en consecuencia, debe consumar su proceso de autodeterminación.

Marruecos, como todo país ribereño signatario de CONVEMAR, puede realizar la ampliación de su plataforma continental más allá de las $200 \mathrm{M}$ siguiendo el procedimiento establecido por el artículo 76 de la Convención. A día de hoy aún no ha efectuado su presentación ante la CSCS. Como tantos Estados que no pudieron realizar su presentación en el período inicialmente establecido se acogió a la ampliación del plazo acordada con carácter general ante la saturación de trabajo a la que se veía sometida la Comisión ${ }^{35}$ que, en el caso de Marruecos, concluía el 31 de mayo de $2017^{36}$. In extremis, el 20 de junio de ese mismo año, Marruecos remitió una nota verbal $^{37}$ dirigida a la División de Asuntos Marítimos y de Derecho del Mar de NN.UU. solicitando que fuera aceptado como presentación preliminar el relatorio informativo ${ }^{38}$ que acompañó a la nota verbal ${ }^{39}$ emitida por Marruecos en 2015 a raíz de la presentación española sobre la extensión de la plataforma continental al oeste de Canarias ${ }^{40}$.

El relatorio informativo de 2015 es un documento de cinco páginas que recoge información muy básica sobre el área marina incluida en la ampliación de la plataforma continental marroquí. No incluye mapas ni datos geológicos ni batimétricos y, básicamente, se limita a manifestar la intención del Reino de Marruecos de realizar los estudios necesarios para llevar a cabo su presentación ante la CLCS. Con este fin, pocas semanas después de la presentación de la nota

${ }^{35}$ COMISIÓN DE LÍMITES DE LA PLATAFORMA CONTINENTAL (2008b): Decisión sobre el volumen de trabajo de la CLPC (SPLOS/183), Nueva York, 20.6.2008, disponible en https://undocs.org/es/SPLOS/183 [consulta: 14 de enero de 2019].

${ }^{36}$ Respuesta del Gobierno a la pregunta escrita planteada por la diputada del Grupo Ciudadanos Dña. Melisa Rodríguez Hernández (184/15057), Madrid, 26 de septiembre de 2017, disponible en www.congreso.es/I12p/e5/e 0050474 n 000.pdf [consulta: 8 de enero de 2019].

${ }^{37}$ Nota Verbal no NV/ATL/N/ 385/2017 de la Misión Permanente de Marruecos ante las Naciones Unidas, de 20 de junio de 2017, disponible en http://www.un.org/Depts/los/clcs new/submissions files/preliminary/1680858.pdf [consulta: 14 de enero de 2019].

${ }^{38}$ Rapport d'informations sur le Plateau Continental Atlantique du Royaume du Maroc au-delà des 200. Milles Marins. Vid. supra nota 28.

${ }^{39}$ Nota Verbal no NV/ATL/N/ 325/2015 de la Misión Permanente de Marruecos ante las Naciones Unidas, de 29 de julio de 2015. Vid. supra nota 22. Como es preceptivo, la nota verbal destaca que la información preliminar presentada no prejuzga la delimitación de la plataforma continental manifestando su disposición a establecer negociaciones con los Estados concernidos con el fin de alcanzar una solución equitativa conforme al Derecho internacional y las disposiciones de CONVEMAR.

${ }^{40}$ En el registro de la CLCS figura el 3 de agosto de 2015 como la fecha de recepción de la información preliminar presentada por Marruecos.

REIM № 26 (junio 2019)

ISSN: $1887-4460$ 
verbal de junio de 2017, se hizo pública la contratación de los servicios del geólogo marino Lindsay Parson, responsable técnico y miembro permanente de la Delegación del Reino Unido para las fronteras marítimas ante las NN.UU. y actual miembro de la Comisión Jurídica y Técnica de la Autoridad Internacional de los Fondos Marinos, para dirigir los trabajos científicos necesarios ${ }^{41}$.

La intención de Marruecos de incluir las aguas del Sahara Occidental en su presentación ante la CLCS fue expresamente manifestada en esas mismas fechas con motivo de la aprobación por el Consejo de Gobierno de dos proyectos de ley ${ }^{42}$ y un proyecto de decreto ${ }^{43}$ relativo a su dominio marítimo. Según la nota informativa difundida por el portavoz del gobierno marroquí:

"ces textes visent à inclure l'espace maritime faisant face aux côtes du Sahara marocain dans I'arsenal juridique national, pour cimenter la tutelle juridique du Maroc sur ces eaux et barrer la route à toutes les allégations remettant en cause la souveraineté du Royaume sur cet espace" ${ }^{44}$.

La intencionalidad política de estos textos legales es múltiple, aunque comparten un propósito común reflejo de la posición jurídica y política que adopta Marruecos frente a esta situación. Vayamos por partes. En primer lugar, con estos desarrollos legislativos se trata de actualizar y completar las coordenadas geográficas de las líneas de base rectas en las costas marroquíes para permitir delimitar sus aguas territoriales con vista a la presentación ante la CSCS del depósito del expediente final de solicitud de extensión de la plataforma continental. A un mismo tiempo se pretende delimitar la ZEE frente a las costas del Sahara Occidental y finalmente se trata de derogar el uso de la línea mediana como criterio de referencia para la demarcación de las fronteras marítimas aplicando, en cambio, el principio de equidad.

Tres objetivos y un propósito común: que la delimitación futura de los espacios marinos entre Marruecos y los Estados vecinos ribereños no se haga sobre el principio de la equidistancia (línea mediana), posición defendida por España, sino sobre el de equidad, criterio que explicamos a continuación.

Este planteamiento elude, por completo, la cuestión de fondo que constituye la usurpación de la soberanía saharaui por parte de Marruecos y las posibles repercusiones que esta acción puede tener en el momento en que Marruecos realice su presentación de ampliación de la plataforma continental ante la CSCS. En este sentido, puede ser coherente con la posición oficial marroquí que considera al Sahara Occidental como parte de su territorio nacional pero resulta conflictivo hacer este planteamiento ante una organización, como Naciones Unidas, cuya consideración oficial sobre ese territorio es radicalmente opuesta.

\footnotetext{
${ }^{41}$ ABC (2017): "Marruecos contrata para su nueva frontera con Canarias al mismo asesor de Londres con Malvinas", 16.7.2017, disponible en www.abc.es/espana/canarias/abci-marruecos-contrata-para-nueva-frontera-canariasmismo-asesor-londres-malvinas-201707161400 noticia.html; H24info (2017): "Le royaume aurait choisi Lindsay Parson pour le conseiller sur le dossier de la délimitation des frontières maritimes du Sahara", 20.7.2017, disponible en www.h24info.ma/actu/voici-lexpert-engage-maroc-delimiter-eaux-territoriales-sahara/ [consulta: 14 de enero de 2019].

42 ROYAUME DU MAROC (2017a): Projet de loi 37-17 modifiant et complétant le Dahir portant loi 1-73-211 du 26 moharrem 1393 (2 mars 1973) fixant la limite des eaux territoriales, disponible en www.legalflashdoc.com/ws/ged/public/dVPcuHWhUydBAT8C [consulta: 14 de enero de 2019]; y Projet de loi 38-17 modifiant et complétant la loi 1.18 instituant une zone économique exclusive de 200 milles marins au large des côtes marocaines.

${ }^{43}$ El proyecto de Decreto 2-17-349 modifica y completa el Decreto 2-75-311 de 11 Rajab 1395 (21 de julio de 1975) que determina las líneas de cierre de las bahías en las costas marroquíes y las coordenadas geográficas del límite de las aguas territoriales marroquíes y ZEE. Este texto estipula el cambio del título del decreto, que a partir de su promulgación determina las coordenadas de las líneas de base utilizadas para delimitar la línea del límite exterior del mar territorial marroquí.

${ }^{44}$ ROYAUME DU MAROC (2017b): Conseil de gouvernement du jeudi 6 juillet 2017, Rabat, Ministère de la Culture et de la Communication, disponible en http://www.maroc.ma/fr/actualites/conseil-de-gouvernement-du-jeudi-6-juillet$\underline{2017}$ [consulta: 14.1.2019].
} 
Este planteamiento no sólo recoge la posición oficial del gobierno marroquí sino también de sus medios académicos, cuyas publicaciones siguen centradas al analizar esta cuestión, salvo contadas excepciones ${ }^{45}$, desde el prisma único de la defensa del principio de equidad como criterio de delimitación de los espacios marinos entre Estados.

Este objetivo constituye una vieja aspiración marroquí desde los tiempos de la independencia del reino y se fundamenta en un argumento jurídico doctrinal que llega hasta nuestros días ${ }^{46}$.

Expuestos de forma resumida, los argumentos marroquíes destacan la importancia de tomar en consideración, a la hora de delimitar los espacios marinos entre Estados con costas enfrentadas, hechos objetivos como pueden ser la longitud de la costa, el volumen de población o la superficie del territorio emergido. En consecuencia, dada la desigualdad manifiesta entre Canarias y Marruecos en estos conceptos la adopción de la línea mediana, que implica un reparto al 50\% entre ambos Estados, debería ser compensada, en aplicación del criterio de equidad, de la siguiente forma: con carácter general, para toda la costa situada entre Tánger y Lagouira (en el extremo meridional del Sáhara Occidental), en una proporción de 7,3 a 1, a favor de Marruecos. Y para la zona específica de costa enfrentada al archipiélago canario (entre los cabos Sim y Dakhla) en una proporción de 5,3 a 1, a favor de Marruecos ${ }^{47}$.

No cuesta imaginar las dificultades a las que se enfrentará una futura negociación bilateral a la hora de definir esos espacios marinos teniendo en cuenta que el único procedimiento admitido para alcanzar un acuerdo consiste en la solución que logren alcanzar los Estados concernidos conforme al Derecho Internacional y las disposiciones de CONVEMAR ${ }^{48}$. Pero esta cuestión, siendo relevante, no elimina la cuestión de fondo que la doctrina marroquí pretende obviar: la existencia del Sáhara Occidental como territorio pendiente de descolonizar.

Como es bien sabido, NN.UU. reconoce al Frente Polisario como representante legítimo del pueblo saharaui ${ }^{49}$ y la República Árabe Saharaui Democrática (RASD) es reconocida por 82 Estados y es miembro de pleno derecho de la Unión Africana. Aunque no sea un Estado con reconocimiento

\footnotetext{
${ }^{45}$ LAHLOU, Abdelkader (2011): "Pour un «Joint development zone» entre le Maroc et l'Espagne au large des Canaries", Annuaire du Droit de la Mer 2009: Tome XIV, pp. 153-170; ABOURABI, Yousra (2014): La découverte de pétrole au large des lles Canaries: un facteur de conflit entre le Maroc et l'Espagne? Centre Interarmées de Concepts de Doctrines et d'Expérimentations (CICDE), disponible https://www.academia.edu/11898884/La d\%C3\%A9couverte de p\%C3\%A9trole au large des lles Canaries facteu r de conflit entre le Maroc et IEspagne [consulta: 26 de marzo de 2019].

${ }^{46}$ Son de referencia las aportaciones del profesor Ihrai: IHRAI, Saïd (2002): "Le contentieux Maroco-Espagnol en matière de délimitation maritime", Annuaire du Droit de la Mer 2009: Tome VII, pp. 199-226; HRAI, Saïd (2006): “Les deux espaces maritimes dans la législation et la pratique marocaine", INSTITUT DU DROIT ÉCONOMIQUE DE LA MER et UNIVERSITÉ MOULAY ISMAÏL: Le plateau continental dans ses rapports avec la zone économique exclusive. Symposium international de Meknès 28 et 29 janvier 2005. París, Pedone, pp.79-90.

${ }^{47}$ ADNANE OUZZINE, Mohammed (2018): “Aperçu sur la délimitation du plateau continental marocain dans l'océan atlantique", en ZAKARIA ABOUDDAHAB, Mohammed; LOUKILI, Miloud y REIFELD, Helmut (dirs.): Le Droit de la Mer: enjeux et perspectives pour le Maroc. Rabat, Konrad-Adenauer-Stiftung, p. 117.

48 ESPOSITO MASSICCI, Carlos (2005), "Sobre el establecimiento de una línea mediana como límite marítimo provisional entre España y Marruecos frente a las costas de las Islas Canarias", Revista Jurídica, no 13, pp. 91-107

49 Resolución $34 / 37$ de la Asamblea General de 21 de noviembre de 1979, disponible en https://undocs.org/sp/A/RES/34/37. Situación reafirmada por el último informe emitido por el Comité Especial encargado de Examinar la Situación con respecto a la Aplicación de la Declaración sobre la Concesión de la Independencia a los Países y Pueblos Coloniales correspondiente a 2018 (A/73/23), pp. 30 y 139, disponible en https://digitallibrary.un.org/record/1642023/files/A 73 23-ES.pdf [consulta : 14 de enero de 2019].
}

REIM No 26 (junio 2019)

ISSN: $1887-4460$ 
internacional pleno, dispone de sus propios órganos de gobierno y su propia capacidad legislativa en virtud de la cual promulgó en 2009 la ley que establece sus propias zonas marítimas ${ }^{50}$. En ella se reafirma, como no podría ser de otro modo, su plena soberanía sobre las aguas que corresponden al territorio ${ }^{51}$.

La RASD ofertó en 2005 la concesión de licencias para realizar prospecciones de búsqueda de gas y petróleo en sus aguas de soberanía ${ }^{52}$ que incluía un mapa de sus aguas territoriales que obviamente se corresponde con el espacio marino sobre el que Marruecos se considera soberano y sobre el que necesariamente habría que emplear como referencia para llevar a cabo la ampliación de la plataforma continental más allá de las 200 M [figura 6]. La reivindicación saharaui sobre esas aguas es permanente y se encuentra asociada al propio proceso de descolonización.

Figura 6: Áreas de prospección de gas y petróleo de la RASD (2005)

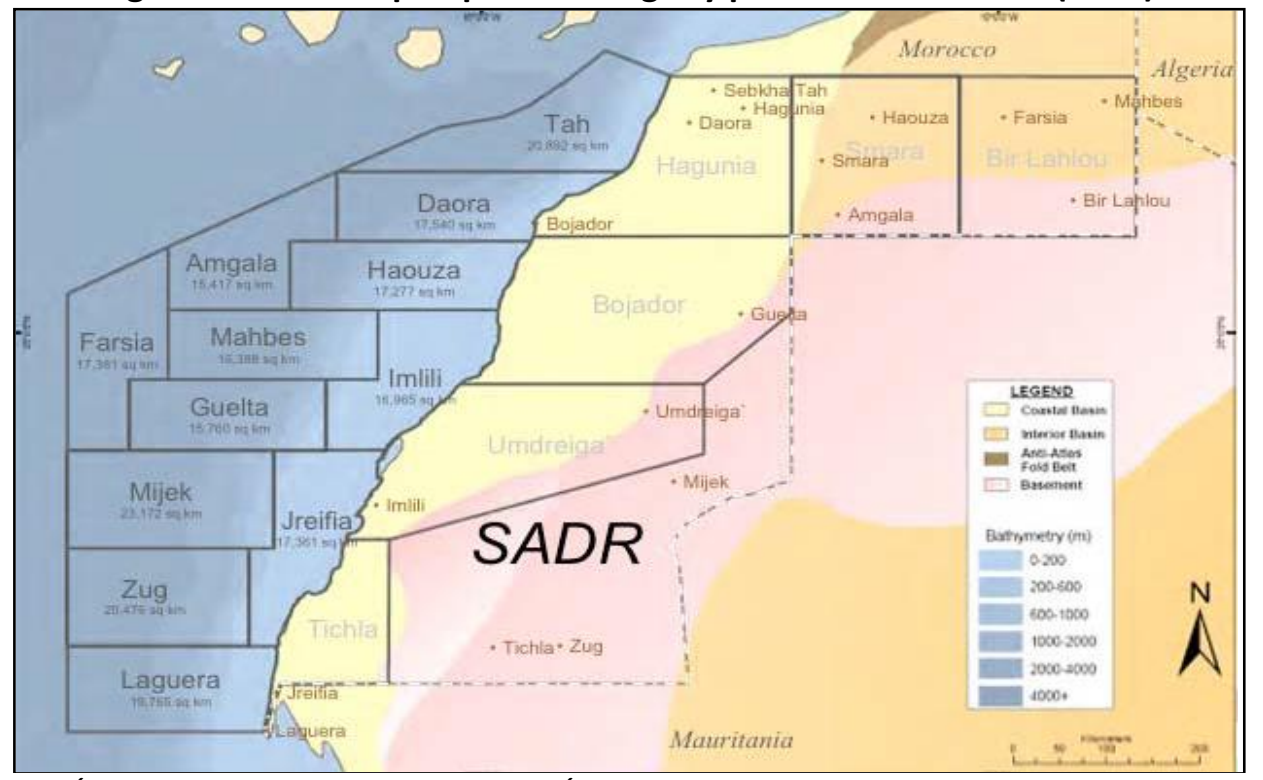

Fuente: RÉPUBLIQUE ARABE SAHARAOUIE DÉMOCRATIQUE (2005): Oil\&Gas Licence Offering 2005

En tanto no haya sido consumado el proceso de autodeterminación del pueblo saharaui y la RASD haya sido reconocida como Estado independiente de pleno derecho, el Sahara Occidental no puede delimitar sus espacios marinos que, como ya se ha indicado repetidamente, sólo puede hacerse a través de un acuerdo con los Estados vecinos concernidos. De la misma forma, el Sahara Occidental tampoco puede llevar a cabo la ampliación de su plataforma continental.

Lo que pone en evidencia ante la CLCS la ley saharaui de 2009 es la pervivencia del proceso de descolonización no consumado sobre el territorio y la falta de legitimidad del Reino de Marruecos para llevar a cabo la ampliación de la plataforma continental a partir de unas aguas cuya soberanía, de forma unilateral, se atribuye. Si finalmente Marruecos incluyera dichas aguas en su presentación posiblemente condicionará las recomendaciones que pueda emitir la Comisión de Límites hasta el punto de comprometer su propio estudio. Por otra parte, si Marruecos renunciara

\footnotetext{
50 RÉPUBLIQUE ARABE SAHRAOUIE DÉMOCRATIQUE (2009): Loi nº3/2009 du 21 Janvier 2009 établissant les zones maritimes de la République Arabe Sahraouie Démocratique, disponible en https://www.wsrw.org/files/dated/200905-15/zee maritime rasd.pdf [consulta : 14 de enero de 2019].

51 “Art.9.1.: La République Arabe Sahraouie Démocratique exerce des droits souverains sur le plateau continental aux fins de son exploration et de l'exploitation de ses ressources naturelles. Ces droits viséssont exclusifs à la République Arabe Sahraouie Démocratique en ce sens que nul ne peut entreprendre de telles activités sans son consentement exprès. Ces droits sont indépendants de l'occupation effective ou fictive, aussi bien que de toute proclamation expresse".

52 RÉPUBLIQUE ARABE SAHRAOUIE DÉMOCRATIQUE (2005): Oil \& Gas Licence Offering 2005, Londres, 17.5.2005, disponible en http://www.sadroilandgas.com/pdfs/Oil GasLicenceOffering17 5 05.pdf [consulta: 14 de enero de 2019].
} 
a incluir esas aguas en su proyecto de extensión de la plataforma continental, decisión muy poco probable, supondría un cambio significativo en la posición tradicionalmente defendida por Rabat que, acaso, pudiera indicar un principio de avance en la solución al contencioso planteado por la descolonización del territorio.

En lo que respecta a la presentación española parece poco probable que esta situación pueda influir sobre las recomendaciones que en su día emita la Comisión pero, sin duda alguna, condicionará la posterior delimitación de esas áreas que, previsiblemente, tardará mucho tiempo en llevarse a efecto.

En cualquier caso, el asunto planteado no queda circunscrito a la determinación de la soberanía sobre el territorio ni a la delimitación de los espacios marinos. También afecta de modo relevante a la futura explotación de los recursos que potencialmente alberga esa extensa área marina y que encuentra su punto crítico, al menos en lo que se conoce hasta el momento, en su zona meridional, donde previsiblemente se superpondrían la plataforma continental ampliada de España y Marruecos / Sahara Occidental. Una zona donde han sido halladas evidencias materiales que abalan la posibilidad de explotar los minerales que se encuentran en su fondo marino.

\section{La riqueza mineral de los montes submarinos canarios y su posible explotación}

Los fondos marinos incluidos en el nuevo espacio de la plataforma continental ampliada, como los del conjunto de la ZEE, representan un vasto potencial para el desarrollo de actividades económicas que no han sido aun convenientemente identificadas. Ello se debe a que las exploraciones realizadas hasta el momento tenían como objetivo procurar argumentos geológicos a la presentación realizada ante la Comisión de Límites. En el curso de esas campañas de investigación oceanográfica fue descubierta una cadena montañosa submarina que muestra una continuidad geológica y geomorfológica con el resto de las cordilleras submarinas que existen en esa región del Atlántico [fig. 7].

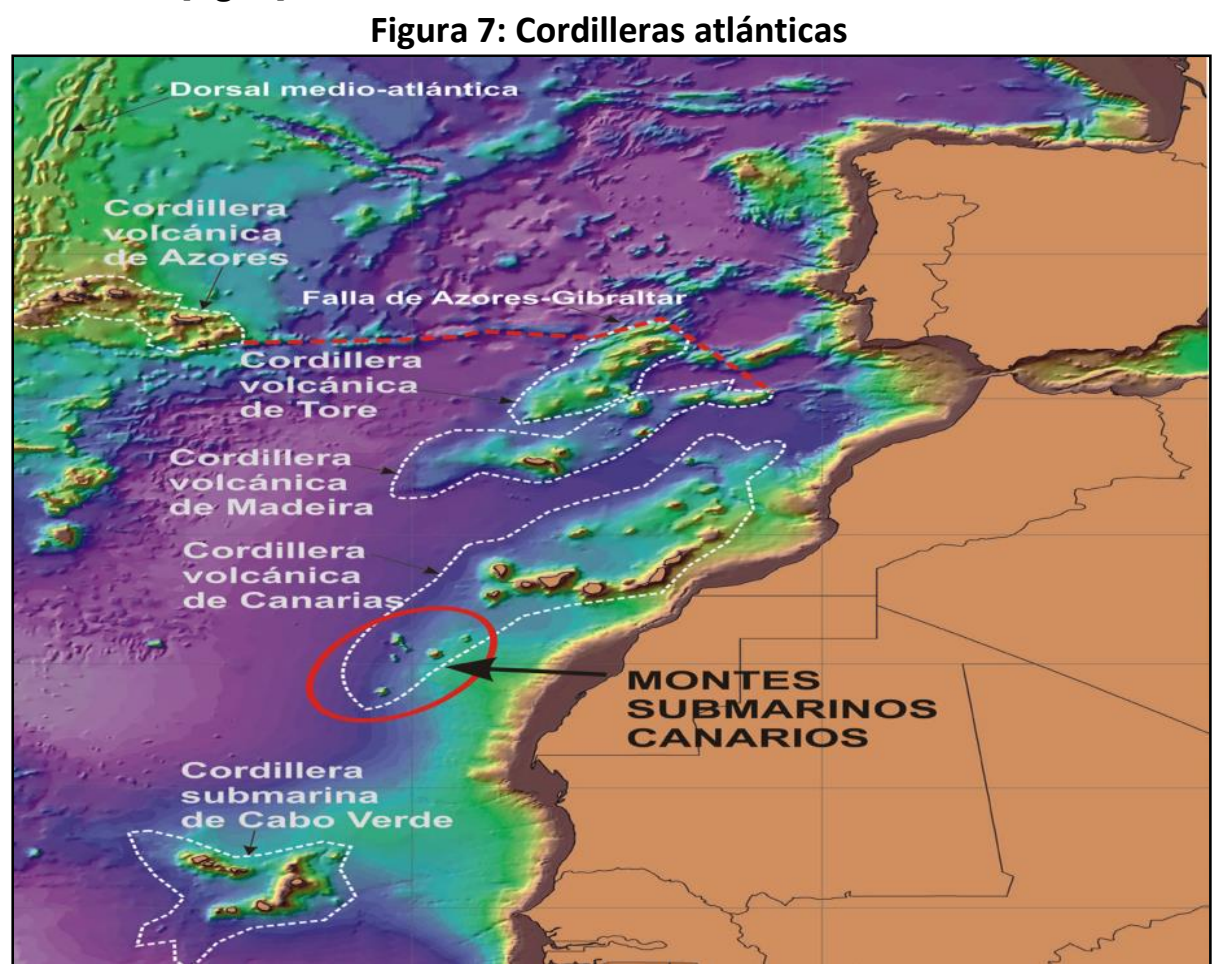

Fuente: SOMOZA, Luis et al. (2015): “¿Una Atlántida canaria?”, p.129

REIM № 26 (junio 2019)

ISSN: $1887-4460$ 
De esta forma, los montes submarinos situados al suroeste de las islas Canarias constituyen una prolongación natural del archipiélago [fig. 8] por lo que, en términos geológicos, no forman parte del continente africano ${ }^{53}$. Esta evidencia permite fundamentar la presentación realizada por España para ampliar la plataforma continental en esa área.

Figura 8: Provincia de los montes submarinos de las islas Canarias

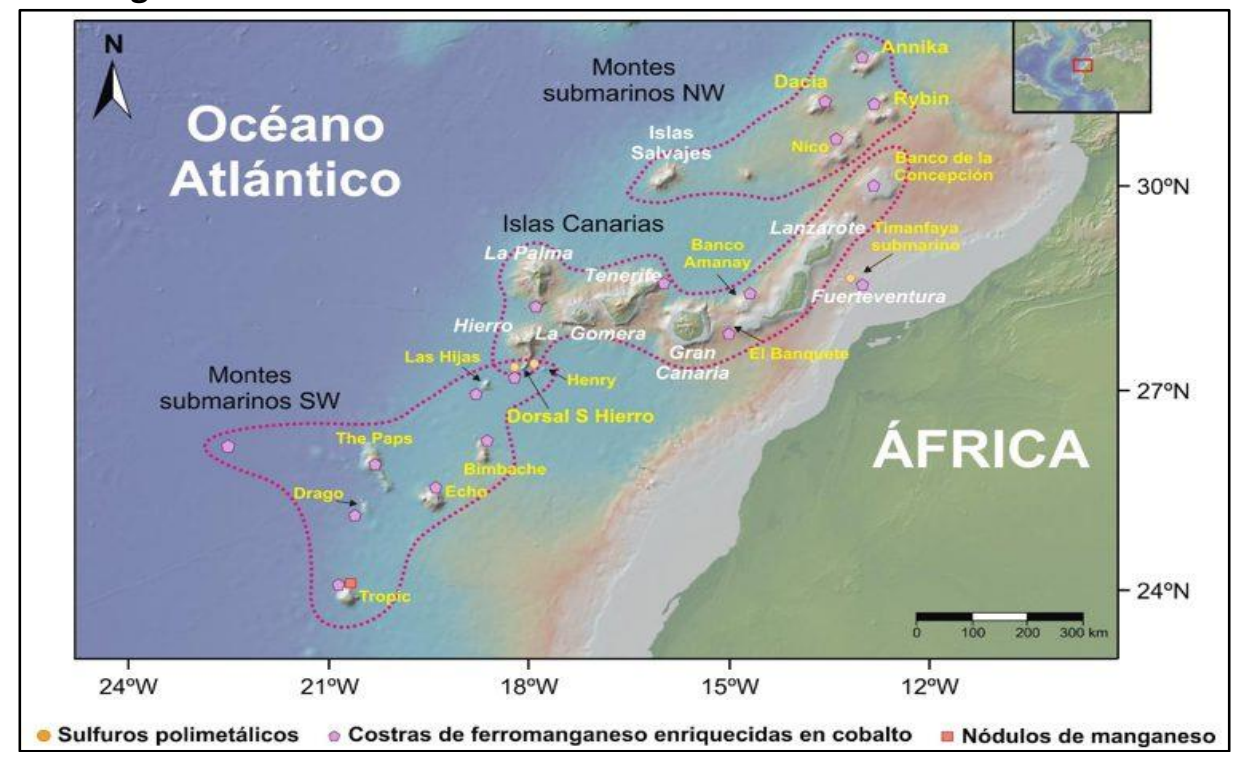

Fuente: MARINO, Egidio et al. (2017): “Llega la era de la minería submarina”

En estos montes submarinos [fig. 9], descubiertos y cartografiados a partir de 2011, han sido hallados depósitos minerales polimetálicos significativos. En especial, costras de ferromanganeso con alto contenido en cobalto ${ }^{54}$ localizadas en los montes Echo, Paps, Drago, Tropic, Bimbache y Las Hijas. Se da la circunstancia de que es los montes más distantes del archipiélago canario donde se encuentran las costras con mayor concentración mineral, en especial en el monte Tropic.

Figura 9: Cordillera submarina de las Islas Canarias

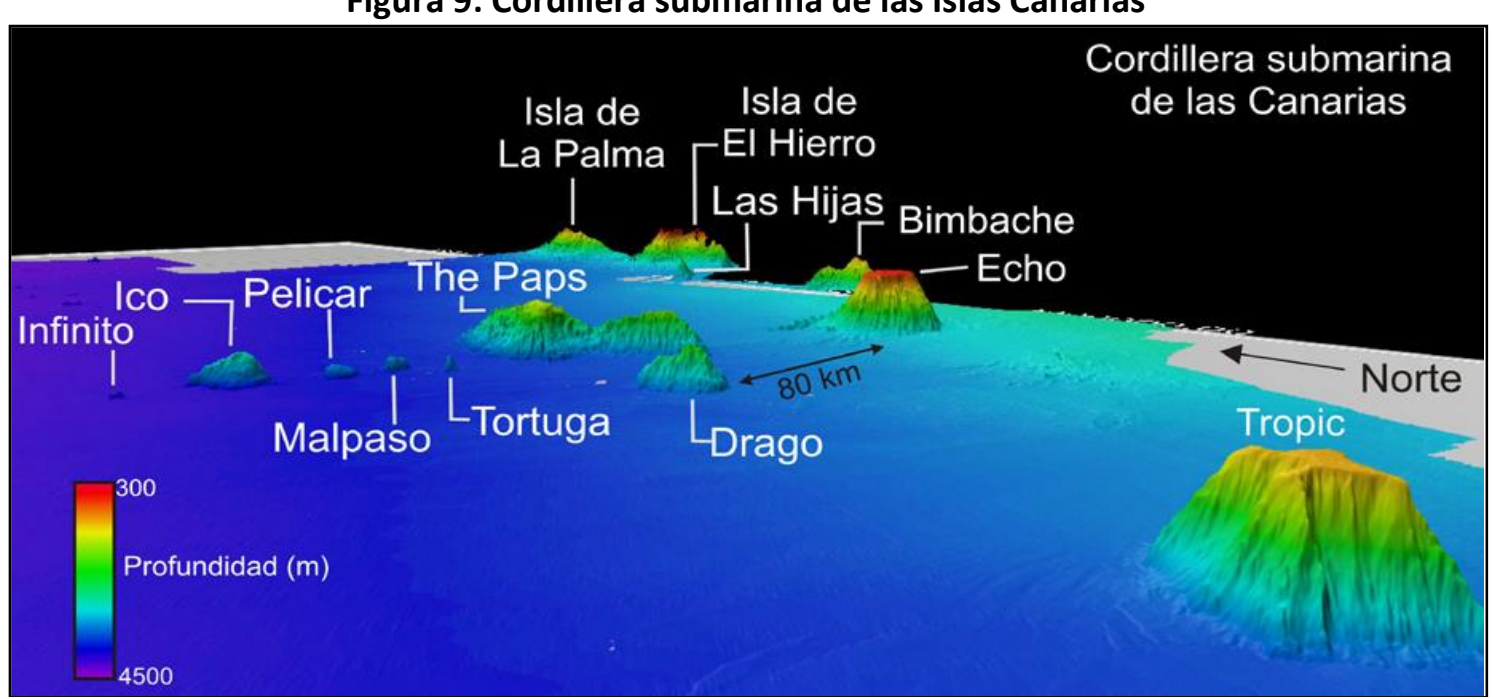

Fuente: MARINO, Egidio et al. (2017a): “Strategic and rare elements ...", p.44.

\footnotetext{
53 INSTITUTO ESPAÑOL DE OCEANOGRAFÍA (2011): Op. cit., p.19.

54 Las costras de ferromanganeso con alto contenido en cobalto se extienden por el lecho marino de todos los océanos, principalmente en los volcanes, montes y mesetas submarinas. Las capas de mayor espesor (hasta $26 \mathrm{~cm}$ ) tienden a encontrarse entre los 800 y 2.500 m de profundidad. Por lo general, presentan una mayor concentración de cobalto que los nódulos y contienen además cantidades significativas de otros metales: níquel, plomo, molibdeno, vanadio, telurio y tierras raras. BLASCO DEL BARRIO, Iker/ GONZÁLEZ, Francisco Javier/ SOMOZA, Luis/ MEDIALDEA, Teresa/ MARINO, Egidio/ BLANCO, Lorena (2016): “Cartografía SIG de Recursos Geológicos Marinos en la Provincia de Montes Submarinos de las Islas Canarias", Macla. Revista de la Sociedad Española de Mineralogía, no 21, p.12.
} 
Tropic $^{55}$ [fig. 10] es el monte más meridional de todos y el más alejado de la isla de Hierro, siendo el único de ellos que se encuentra más allá del límite de $200 \mathrm{M}$ de la plataforma continental, precisamente en el área de superposición de la plataforma continental ampliada. La singularidad del Tropic radica en que allí se ha encontrado el denominado por la prensa" "mayor yacimiento del mundo de telurio" con unas reservas estimadas de $2600 \mathrm{t}$, lo que representa el $10 \%$ de las reservas mundiales de este mineral que se emplea en la fabricación de productos tecnológicos. La difusión de la noticia, filtrada por científicos británicos que participaron en una expedición conjunta con España ${ }^{57}$, se realizó en términos sensacionalistas alentando unas expectativas de explotación, y beneficio, prácticamente inmediatas, que recordaba a la polémica vivida hace unos años con motivo de las prospecciones petrolíferas llevadas a cabo entre Canarias y la costa africana.

Figura 10: Monte submarino Tropic

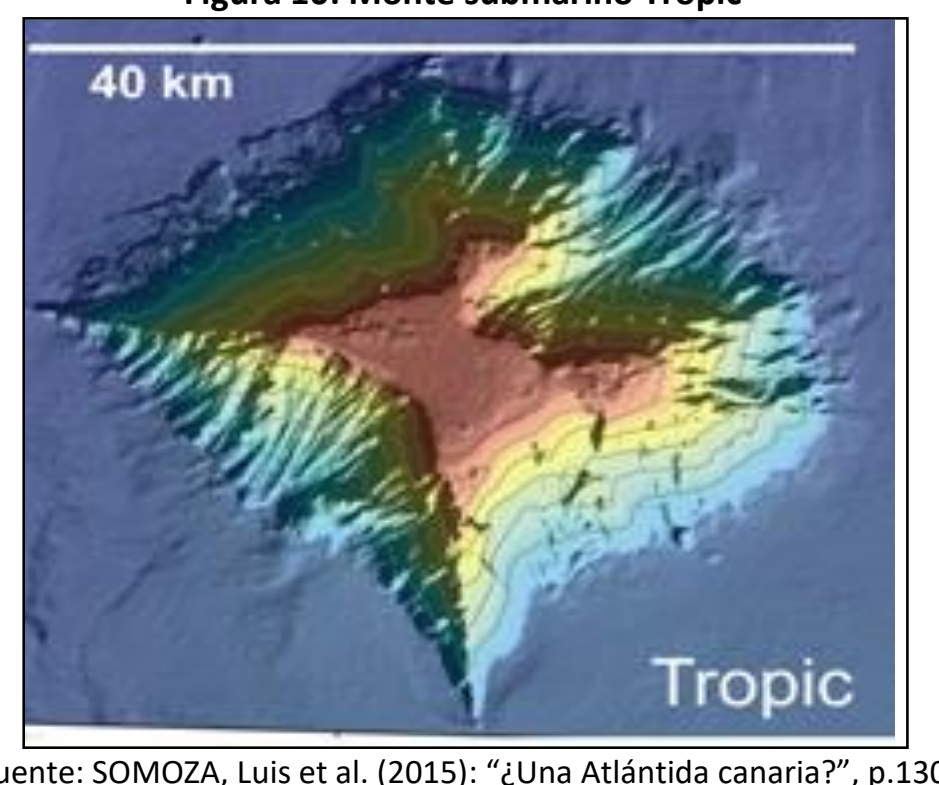

El que exista el yacimiento y sea potencialmente posible su explotación es una cuestión. Otra muy distinta es que se vaya a producir próximamente, aún en el medio plazo. El desarrollo tecnológico ha permitido que la minería en aguas profundas haya pasado, en tan sólo una década, de ser una posibilidad futurista a convertirse en una realidad probable, aunque todavía no cercana en el tiempo, al menos en estas aguas. Se trata de una actividad sin precedentes que plantea un desafío extraordinario y exige una enorme preparación previa (en investigación y medios) que impide que pueda ser acometida en un plazo breve. En primer lugar es necesario hacer estudios geológicos mucho más detallados de los realizados hasta el momento. Después hay que realizar una evaluación económica sobre la rentabilidad de la explotación de los recursos que se descubran y,

\footnotetext{
${ }^{55}$ Se trata de un monte de unos $1000 \mathrm{~km} 2$ de superficie, con una altura de $3000 \mathrm{~m}$ sobre el fondo oceánico. Su cima se encuentra a 1000 m de la superficie del mar. Se sitúa a 264 M al SW de Canarias y a 241 M al W de la costa del Sahara Occidental.

${ }^{56}$ ABC (2017a): "Ocho países se disputan el tesoro minero hallado en aguas de Canarias", ABC (17.4.2017), disponible en $\quad$ https://www.abc.es/sociedad/abci-ocho-paises-disputan-tesoro-minero-hallado-aguas-canarias201704172218 noticia.html [consulta: 18 de enero de 2018]

57 INSTITUTO GEOLÓGICO Y MINERO DE ESPAÑA (2016): Expedición internacional JC142, con participación de organismos científicos de España, Reino Unido y Brasil, (octubre - diciembre 2016), nota de prensa del 19.10.2016, disponible

www.igme.es/SalaPrensa/NotasPrensa/2016/10/NOTA\%20DE\%20PRENSA\%20EXPEDICI\%C3\%93N\%20INTERNACIONA L\%20JC142.pdf [consulta: 18 de enero de 2019]
} 
en tercer lugar, pero no menos importante, se deberán superar las exigencias de viabilidad medioambiental establecidas por la Unión Europea y la propia legislación nacional. En el caso de haber cumplido todos esos requisitos, se podría iniciar la fase de explotación que requeriría, en primer lugar, una serie de prospecciones mineras mucho más detalladas de cada una de las zonas susceptibles de ser explotadas. A continuación se deberían realizar los necesarios desarrollos tecnológicos de minería submarina (buques mineros, bombas de succión de mineral, maquinas extractoras robotizadas, etc.) adaptados a las condiciones orográficas específicas de cada yacimiento (ya que la misma maquinaria no puede operar sobre un fondo plano o en desnivel). $Y$ finalmente se podría proceder a la extracción del mineral cuya rentabilidad depende, en última instancia, del precio que fijen los mercados internacionales.

Incluso para un mineral tan escaso y demandado como el telurio, resulta difícil determinar si su explotación submarina podría competir con el precio de mercado del mineral extraído en superficie. El telurio es un mineral extremadamente raro en la corteza terrestre (tres veces más escaso que el oro y sólo comparable al platino) que tiene una elevada demanda potencial asociada a nuevas tecnologías empleadas en la construcción de paneles solares y generadores termoeléctricos que representan, aproximadamente, el $70 \%$ de la demanda mundial. También se usa para reducir la propiedad corrosiva del ácido sulfúrico, por lo que puede ser necesario para el desarrollo de la industria eólica marina ${ }^{58}$.

Se puede obtener telurio refinando lodos de cobre, como ocurre con otros metales (oro, plata, platino, arsénico y selenio). La gestión de esos residuos permite a cualquier empresa especializada en la producción de cobre, poder extraer telurio. Así se obtiene el $90 \%$ del telurio producido, unas 500/550 t anuales. El precio del telurio ha ido escalando desde los 82 US\$ por $\mathrm{Kg}$, en 2007, a los 349 US\$ en 2011. En la actualidad, su precio por kilo, en lingote, oscila entre los 200 y 500 US\$59. Tendría que crecer la demanda mundial de forma extraordinaria para que el precio de venta del producto permitiera compensar los previsibles costes asociados a la extracción submarina.

Si la viabilidad, y rentabilidad, de la actividad minera submarina no está asegurada, las dudas sobre su ejecución práctica se multiplican al considerar el deterioro medioambiental que conlleva esta actividad. Las asociaciones ecologistas y conservacionistas exigen su completa prohibición ${ }^{60}$ y las Naciones Unidas, un respeto escrupuloso al medio marino61. El Parlamento Europeo ha solicitado una moratoria indefinida para este tipo de actividades ${ }^{62}$. Aunque no todos los científicos

\footnotetext{
58 ABC (2017b): "Qué es el telurio de Canarias y cómo se podrá sacar del agua", ABC (18.4.2017), disponible en www.abc.es/espana/canarias/abci-telurio-canarias-y-como-saldra-agua-201704180249 noticia.html [consulta: $18 \mathrm{de}$ enero de 2019].

${ }^{59}$ GEORGE, Micheal W. (2013): "Mineral Resource of the Month: Tellurium”, Arth Magazine (American Geosciences Institute), vol. 58 no3, p.57, disponible en https://www.earthmagazine.org/article/mineral-resource-month-tellurium; Alibaba.com, disponible

en

https://spanish.alibaba.com/trade/search?fsb=y\&IndexArea=products\&Catld=\&SearchText=kilo+telurio+lingote+preci o\&selectedTab=products\&viewType=GALLERY [consulta: 18 de enero de 2019].

${ }^{60}$ En 2004 se creó una plataforma internacional que agrupa a más de 70 organizaciones con el objetivo de promover la protección integral de las áreas profundas de los océanos: The Deep Sea Conservation Coalition (DSCC www.savethehighseas.org). Un estudio sobre los riesgos ecológicos de la minería submarina puede consultarse en GREENPACE (2013): Deep Seabed Mining. An urgent wake-up call to protect our oceans, disponible en www.greenpeace.org/international/Global/international/publications/oceans/2013/Deep-Seabed-Mining.pdf [consulta: 18 de enero de 2019].

61 NACIONES UNIDAS (2006 y 2009): Resolución 61/105 (8.12.2006) y Resolución 64/72 (4.12.2009), ambas sobre pesca sostenible, disponibles en www.un.org/es/comun/docs/?symbol=A/RES/61/105 Y www.un.org/es/comun/docs/?symbol=A/RES/64/72, respectivamente [consulta: 18 de enero de 2019].

62 PARLAMENTO EUROPEO (2018): Resolución del Parlamento Europeo, de 16 de enero de 2018, sobre la gobernanza internacional de los océanos: una agenda para el futuro de nuestros océanos en el contexto de los Objetivos de Desarrollo Sostenible para $2030 \quad(2017 / 2055($ INI)), $\quad$ disponible http://www.europarl.europa.eu/sides/getDoc.do?type=TA\&reference=P8-TA-2018-0004\&language=ES\&ring=A8-
} 
comparten una visión catastrofista sobre esta actividad existe un consenso sobre el desconocimiento actual de las posibles implicaciones futuras respecto del equilibrio de los ecosistemas marinos y, a largo plazo, sobre las condiciones climáticas del planeta ${ }^{63}$.

Es imperativo realizar una reflexión sobre este tipo de actividades submarinas de explotación industrial que una vez iniciadas no permiten restablecer las condiciones originales del medio marino. La fragilidad de unos ecosistemas submarinos que se remontan al origen de la vida en la Tierra y que ejercen una función esencial en la dinámica y estabilidad del océano pueden ser definitivamente destruidos por una actividad efímera y con efectos importantes, pero no especialmente determinantes, para el desarrollo humano ${ }^{64}$. Esta reflexión debe hacerse extensiva al conjunto de la sociedad a la cual se le ha presentado el descubrimiento del telurio en el monte Tropic como un nuevo "el dorado" con potencialidades ilimitadas.

A los condicionantes mencionados que hacen inviable una próxima explotación de estos yacimientos minerales debemos sumar su localización geográfica que los sitúan en la previsible área de solapamiento entre las plataformas continentales ampliadas de España y Marruecos / Sahara Occidental. La jurisdicción sobre la explotación de esos fondos marinos no estará atribuida hasta que los Estados concernidos hayan realizado la delimitación de sus respectivos espacios marinos. Lo cual, en sí mismo, resulta difícil de lograr en las actuales circunstancias. Si a ello se le suma la condición del Sahara Occidental como territorio no autónomo que debe consumar su proceso de descolonización puede comprenderse la dificultad para alcanzar un acuerdo.

Tampoco parece posible que Marruecos pudiera beneficiarse de la explotación de las riquezas submarinas de esas aguas del mismo modo en que lleva décadas disponiendo de los recursos naturales del Sahara Occidental, bien sea la pesca ${ }^{65}$, fosfatos ${ }^{66}$ o autorizando las prospecciones de

2017-0399; REVISTA INGENIERÍA NAVAL (2018): “El Parlamento Europeo pide una moratoria para la minería submarina", Revista ingeniería naval, no. 967, 2018, disponible en https://sectormaritimo.es/moratoria-mineriasubmarina [consulta: 18 de enero de 2019].

63 THE GUARDIAN (2017): "Is deep sea mining vital for a greener future - even if it destroys ecosystems?",The Guardian (4.6.2017), disponible en www.theguardian.com/environment/2017/jun/04/is-deep-sea-mining-vital-forgreener-future-even-if-it-means-destroying-precious-ecosystems [consulta: 18 de enero de 2019].

${ }^{64}$ CHANTAL RIVEIRO, Marta (2015): "Entre o apelo dos recursos minerais e a protecção dos ecossistemas vulneráveis do mar profundo em Portugal. Enquadramento legal, sistema de competências e ordenamento", en CHANTAL RIVEIRO, Marta (coord.): 20 Anos da entrada em vigor da CNUDM: Portugal e os recentes desenvolvimentos no Direito do Mar. Porto, CIIMAR - FDUP, pp.55-108; PONTE IGLESIAS, Ma Teresa (2018): Escenario y contexto de la seguridad marítima en el horizonte 2050: minería marina y seguridad ambiental. Madrid, IEEE, 2018 (documento de investigación 20/2018) disponible en http://www.ieee.es/Galerias/fichero/docs investig/2018/DIEEEINV202018SeguridadMaritima.pdf [consulta: 18 de enero de 2019].

65 En febrero de 2018 el Tribunal de Justicia de la UE (TJUE) emitió una sentencia sobre el acuerdo pesquero entre la UE y Marruecos dictaminando que las aguas del Sáhara Occidental no forman parte del territorio marroquí. Aunque el Tribunal no invalida el acuerdo de pesca establece que no se debe aplicar a las aguas colindantes al territorio saharaui. UNIÓN EUROPEA (2018): Sentencia del Tribunal de Justicia (Gran Sala) de 27 de febrero de 2018, disponible en http://curia.europa.eu/juris/document/document.jsf?text=\&docid=199683\&doclang=ES. Un Nuevo acuerdo pesquero debería precisar con claridad las siguientes cuestiones: "An FPA with Morocco that covers waters outside WS must conform with the following conditions: o The agreement should make clear that it does not cover WS as a part of the territory of Morocco o The agreement must be in accordance with the wishes and interests of the people of WS", BRING, Ove et alii (2011): Western Sahara and the EU-Morocco Fisheries Partnership Agreement (FPA), Swedish legal opinion (17.2.2011) disponible en https://www.wsrw.org/files/dated/2011-02-17/swedish legalopinion 16.02.2011.pdf [consulta: 18 de enero de 2019].

66 “(...) with respect to the use of the phosphates extracted from the Bou Craa mines in Western Sahara, while the U.S. Trade Representative has confirmed that the free trade agreement entered into by Morocco and the United States 
gas y petróleo ${ }^{67}$ sobre el territorio68. La diferencia radica en que todos esos recursos se encuentran situados en el territorio o ZEE del Sahara Occidental mientras que los yacimientos minerales submarinos se encuentran dentro del área que correspondería a la plataforma continental ampliada del territorio.

En tanto no se materialice la ampliación de la plataforma continental España, Marruecos o cualquier otro Estado puede realizar campañas de investigación y exploración oceanográficas en el área del monte Tropic. Incluso su explotación, siempre que lo autorice la Autoridad Internacional de Fondos Marinos, único órgano con competencia en la materia sobre aquellas áreas del fondo del océano que no se encuentran bajo jurisdicción nacional (art. 151 CONVEMAR).

Por otra parte, en el caso de hallarse nuevos yacimientos minerales en algún otro de los montes que componen la cordillera submarina canaria, de encontrarse dentro de los límites actuales de la PC española, el gobierno español tendría competencias para llevar a cabo su explotación.

\section{Conclusiones}

Como ha podido observarse, el objeto de estudio abordado resulta particularmente complejo por la acumulación y superposición de factores que inciden directamente sobre él. No obstante no todos los problemas planteados comparten la misma dimensión, ni necesariamente la falta de solución de alguno de ellos debe bloquear a los demás.

La primera cuestión que se plantea corresponde al futuro de la presentación española ante la Comisión de Límites. A la espera de que se emitan sus recomendaciones todo indica que confirmará el límite externo de la plataforma continental ampliada presentado por España. Cabe esperar que el tiempo que previsiblemente transcurra hasta ese momento sea aprovechado por la diplomacia española para avanzar en la delimitación de los espacios marinos con los Estados vecinos. Con Portugal existe una esperanza razonable de que se pueda alcanzar un acuerdo global que permita definir las fronteras marítimas aún pendientes. El reciente acuerdo alcanzado sobre la desembocadura de los ríos Miño y Guadiana ${ }^{69}$ allana el camino en esa dirección. Con Marruecos, en cambio, parece del todo imposible.

excludes the territory of Western Sahara, such exclusion does not necessarily prevent the importation of products and resources extracted from Western Sahara into the United States. To the extent Bou Craa phosphates are declared on U.S. customs declarations to be from Morocco, such importation may be in violation of both international law and U.S. customs regulations.

67 “(...) in the present case, the contracts for oil reconnaissance and evaluation do not entail exploitation or the physical removal of the mineral resources, and no benefits have as of yet accrued. The conclusion is, therefore, that, while the specific contracts which are the subject of the Security Council's request are not in themselves illegal, if further exploration and exploitation activities were to proceed in disregard of the interests and wishes of the people of Western Sahara, they would be in violation of the international law principles applicable to mineral resource activities in Non-Self-Governing Territories" CORELL, Hans (2002): Letter dated 29 January 2002 from the UnderSecretary-General for Legal Affairs, the Legal Counsel, addressed to the President of the Security Council (A/2002/161), Naciones Unidas (12.2.2002), disponible en http://www.arso.org/Olaeng.pdf [consulta: 18 de enero de 2019].

68 KINGSBURY, Damien (ed.) (2016): Western Sahara. International law, justice and natural resources. Londres N.York, Routledge.

69 Tratado entre el Reino de España y la República Portuguesa por el que se establece la línea de cierre de las desembocaduras de los ríos Miño y Guadiana y se delimitan los tramos internacionales de ambos ríos, hecho en Vila Real el 30 de mayo de 2017. BOE núm. 189, de 6 de agosto de 2018 disponible en https://www.boe.es/boe/dias/2018/08/06/pdfs/BOE-A-2018-11228.pdf [consulta: 19 de enero de 2019]. Vid. JIMÉNEZ GARCÍA-CARRIAZO, A. (2018): "Primeros pasos hacia la nueva frontera marítima hispano-lusa: el cierre de la desembocadura del río Guadiana", Paix et Sécurité Internationales, № 6, pp. 181-190 (DOI http://dx.doi.org/10.25267/Paix sécur int.2018.i6.10 ). 
La razón por la cual Marruecos y España no han delimitado sus respectivos espacios marinos tiene un fundamento histórico. Es consecuencia de la reivindicación marroquí sobre las plazas de soberanía española localizadas en la costa mediterránea del continente africano. A esa cuestión histórica, carente de respaldo jurídico internacional, se sumó a partir de 1976 la ocupación marroquí de Sahara Occidental y su pretensión de anexionarlo a su territorio nacional. Desde entonces Marruecos ha realizado todos los esfuerzos imaginables para lograr un reconocimiento internacional a sus pretensiones sin lograr que NN.UU. haya modificado su calificación sobre el Sahara Occidental como territorio no autónomo que debe consumar su proceso de autodeterminación. Si bien Marruecos puede llevar a cabo una ocupación efectiva del territorio, de facto es la potencia ocupante, cada vez le resulta más difícil que se admita internacionalmente la explotación de los recursos sin contar con la población saharaui: las opiniones jurídicas emitidas y la sentencia del Tribunal de Justicia de la UE sobre el acuerdo pesquero no dejan lugar a dudas.

La forma en que finalmente Marruecos formalice su presentación ante la CLCS va a influir directamente sobre este contencioso descolonizador. Si incluye las aguas saharauis, como parece ser su intención, se arriesga a que la CLCS no emita sus recomendaciones sobre el área marítima correspondiente a las costas del Sahara Occidental o que, sencillamente, las rechace. $Y$ si Marruecos no las incluye sentaría un precedente que acaso pudiera abrir una vía de entendimiento con el Frente Polisario. Pero es muy poco probable que eso se produzca. En primer lugar porque es difícil de imaginar que Marruecos vaya a renunciar a su proyecto expansionista por ampliar su plataforma continental. En segundo lugar porque la PC que se encuentra bajo su jurisdicción apenas puede ser ampliada al tener frente a sus costas los archipiélagos de Canarias y Madeira [figura 11]. En consecuencia, a Marruecos no le queda más alternativa que hacer su presentación incluyendo las aguas saharauis o no hacerla, renunciando por tanto a llevar a cabo la ampliación de la plataforma continental. Aunque esta opción tampoco supondría una solución ya que la RASD previsiblemente mantendría esa aspiración y en caso de lograr la independencia procedería a hacerlo.

Figura 11: Panorama global de las fronteras marítimas de Portugal pendientes de delimitar ${ }^{70}$

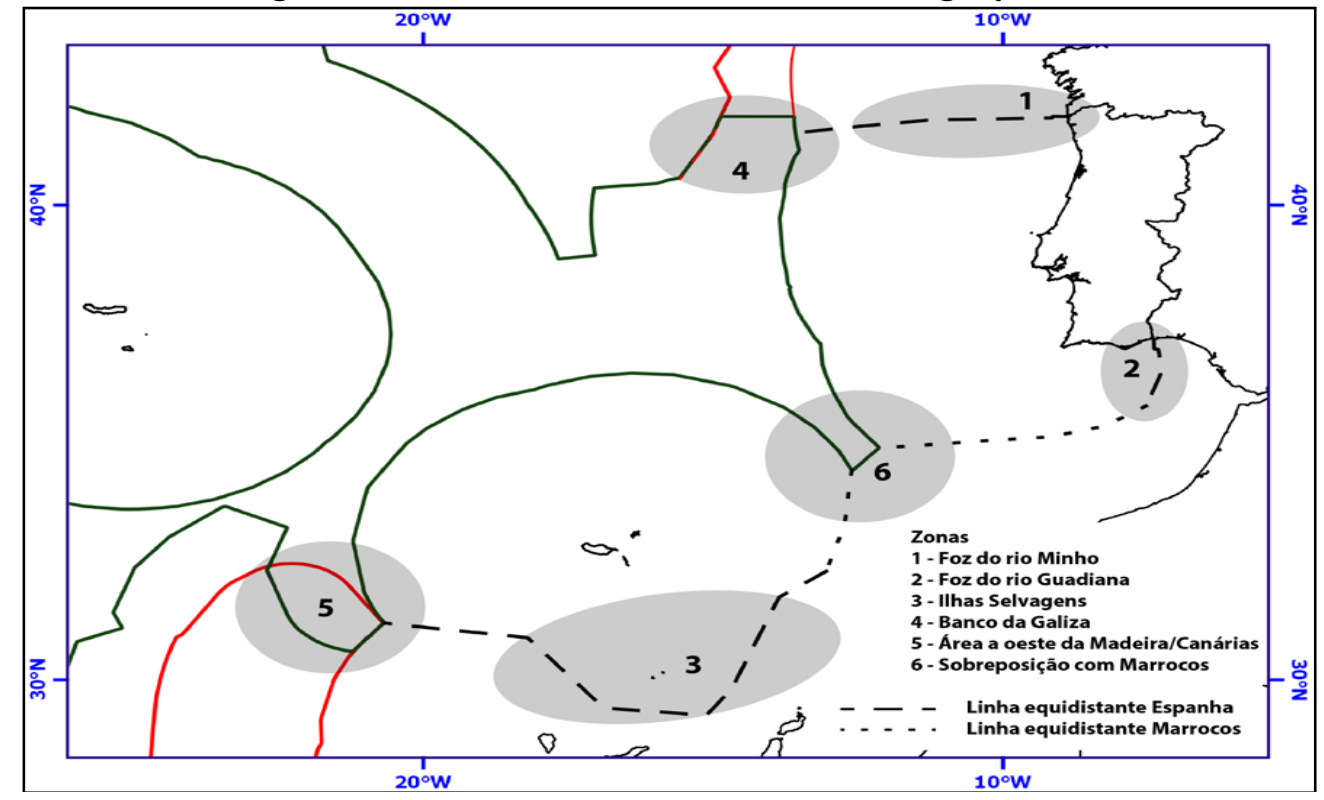

Fuente: NEVES COELHO (2017): “A delimitação dos espaços marítimos de Portugal”, p.102

${ }^{70}$ El área 6 correspondería a la zona de solapamiento entre las Plataformas Continentales extendidas de Portugal y Marruecos.

REIM № 26 (junio 2019)

ISSN: $1887-4460$ 
Ninguna de estas posibilidades condiciona las recomendaciones que pueda hacer la Comisión de Límites respecto de la presentación española pero hacen muy difícil que, llegado el caso, se pueda proceder a una delimitación de fronteras en esa área marítima específica. Esta circunstancia condicionará la posible explotación del yacimiento mineral submarino del monte Tropic por parte de las autoridades españolas, aunque sí pueda hacerse a través de la Autoridad Internacional de Fondos Marinos por encontrarse en La Zona internacional de su competencia en tanto no se produzca la extensión de la plataforma continental por parte de los Estados ribereños. En el caso de hallarse nuevos yacimientos en los demás montes submarinos que se localizan en la PC de Canarias su explotación podría realizarse a través de la jurisdicción española. Hay que insistir, en todo caso, lo quimérica que resulta esta posibilidad que aunque técnicamente parece realizable con la tecnología disponible en la actualidad, el impacto medioambiental que causaría y el precio de mercado de los minerales que se obtendrían hacen muy improbable su explotación.

\section{Referencias}

ABOURABI, Yousra (2014): La découverte de pétrole au large des lles Canaries : un facteur de conflit entre le Maroc et l'Espagne? Centre Interarmées de Concepts de Doctrines et d'Expérimentations

(CICDE)

https://www.academia.edu/11898884/La d\%C3\%A9couverte de p\%C3\%A9trole au large des lles Cana ries facteur de conflit entre le Maroc et IEspagne

ADNANE OUZZINE, Mohammed (2018): 'Aperçu sur la délimitation du plateau continental marocain dans l'océan atlantique', en ZAKARIA ABOUDDAHAB, Mohammed; LOUKILI, Miloud y REIFELD, Helmut (dirs.): Le Droit de la Mer: enjeux et perspectives pour le Maroc. Rabat, KonradAdenauer-Stiftung, pp. 91-123.

ATMANE, Tarik (2007): España y Marruecos frente al derecho del mar. A Coruña, Netbiblo.

BLASCO DEL BARRIO, Iker; GONZÁLEZ, Francisco Javier; SOMOZA, Luis; MEDIALDEA, Teresa; MARINO, Egidio y BLANCO, Lorena (2016): 'Cartografía SIG de Recursos Geológicos Marinos en la Provincia de Montes Submarinos de las Islas Canarias', Macla. Revista de la Sociedad Española de Mineralogía, no 21, pp.11-13 (http://www.ehu.eus/sem/macla_pdf/macla21/Macla21_011.pdf). BRING, Ove et al. (2011): Western Sahara and the EU-Morocco Fisheries Partnership Agreement (FPA), Swedish legal opinion (17.2.2011) (https://www.wsrw.org/files/dated/2011-0217/swedish legal-opinion 16.02.2011.pdf).

CHANTAL RIVEIRO, Marta (2015): 'Entre o apelo dos recursos minerais e a protecção dos ecossistemas vulneráveis do mar profundo em Portugal. Enquadramento legal, sistema de competências e ordenamento', en CHANTAL RIVEIRO, Marta (coord.): 20 Anos da entrada em vigor da CNUDM: Portugal e os recentes desenvolvimentos no Direito do Mar. Porto, CIIMAR FDUP, pp.55-108.

ESPOSITO MASSICCI, Carlos (2005): 'Sobre el establecimiento de una línea mediana como límite marítimo provisional entre España y Marruecos frente a las costas de las Islas Canarias', Revista Jurídica, no 13, pp. 91-107.

FARAMIÑÁN GILBERT, Juan Manuel de(2014): 'Consideraciones jurídicas sobre la extensión de la plataforma continental (PC) más allá de las 200 (M) millas marinas (algunas referencias a la plataforma continental española)', en BOU FRANCH, Valentín, JUSTE RUIZ, José (dirs.) y SÁNCHEZ PATRÓN, José Manuel (coord.): Derecho del mar y sostenibilidad ambiental en el Mediterráneo, Valencia, Tirant, pp. 59-86.

GARCÍA PÉREZ, Rafael; NEVES COELHO, Paulo y FERREIRA RODRIGUES, Teresa (coords) (2017): $A$ extensão das plataformas continentais: Portugal e Espanha, perspectivas $e$ realidades.Porto,Fronteira do Caos.

GARCÍA PÉREZ, Rafael (2017): 'La delimitación de los espacios marinos entre España y Portugal en caso de ampliarse la plataforma continental más allá de las 200 millas', en GARCíA PÉREZ, Rafael; NEVES COELHO, Paulo y FERREIRA RODRIGUES, Teresa (coords): A extensão das plataformas continentais: Portugal e Espanha, perspectivas e realidades.Porto,Fronteira do Caos, pp.107-138. 
GARCÍA QUINTELA, Adolfo (2015): El Ministerio de la Mar: una opción que proporciona una visión integral y optimiza recursos. Madrid, UNED (tesis doctoral).

GEORGE, Micheal W. (2013): 'Mineral Resource of the Month: Tellurium', Arth Magazine (American Geosciences Institute), vol. 58 no3, p.57, (https://www.earthmagazine.org/article/mineral-resource-month-tellurium).

GUTIÉRREZ CASTILLO, Víctor L. (2004): España y sus fronteras en el mar. Madrid, Dykinson Universidad de Córdoba.

GUTIÉRREZ CASTILLO, Víctor L. (2017): 'La delimitación de los espacios marinos', en MARIÑO MÉNDEZ, Fernando M. (dir.), Instrumentos y regímenes de cooperación internacional, Madrid, Trotta, pp.383-403.

IHRAI, Saïd (2002): 'Le contentieux Maroco-Espagnol en matière de délimitation maritime', Annuaire du Droit de la Mer 2009: Tome VII, pp. 199-226.

IHRAI, Saïd (2006): 'Les deux espaces maritimes dans la législation et la pratique marocaine', INSTITUT DU DROIT ÉCONOMIQUE DE LA MER et UNIVERSITÉ MOULAY ISMAÏL: Le plateau continental dans ses rapports avec la zone économique exclusive. Symposium international de Meknès 28 et 29 janvier 2005. París, Pedone, pp.79-90.

JIMÉNEZ GARCÍA-CARRIAZO, Ángeles (2018): La ampliación de la plataforma continental más allá de las doscientas millas marinas. Especial referencia a España. Madrid, Dykinson, pp.253-268.

JIMÉNEZ GARCÍA-CARRIAZO, Ángeles (2018): 'La plataforma continental de las Islas Canarias: ampliación y cuestiones afines', Revista Española de Derecho Internacional, vol. 70, no 2, pp. 23926 (http://dx.doi.org/10.17103/redi.70.2.2018.3.01).

JIMÉNEZ GARCÍA-CARRIAZO, A. (2018): "Primeros pasos hacia la nueva frontera marítima hispanolusa: el cierre de la desembocadura del río Guadiana", Paix et Sécurité Internationales, № 6, pp. 181-190 (http://dx.doi.org/10.25267/Paix sécur int.2018.i6.10).

KINGSBURY, Damien (ed.) (2016): Western Sahara. International law, justice and natural resources. Londres - N.York, Routledge.

LACLETA MUÑOZ, José Manuel (2014): 'La delimitación de los espacios marinos en España: a modo de balance', en MARTíN Y PÉREZ DE NANCLARES, José (dir.): España y la práctica del Derecho Internacional. Madrid, Escuela Diplomática, pp.115-119 (www.exteriores.gob.es/Portal/es/Ministerio/EscuelaDiplomatica/Documents/Coleccion ED 20 web.pdf).

LAHLOU, Abdelkader (2011): 'Pour un «Joint development zone» entre le Maroc et l'Espagne au large des Canaries', Annuaire du Droit de la Mer 2009: Tome XIV, pp. 153-170.

MAGNÚSSON, Bjarni Már (2015): The continental shelf beyond 200 nautical miles: delineation, delimitation and dispute settlement. Leiden - Boston, Brill - Nijhoff.

MARINO, Egido; GONZÁLEZ, F. Javier; SOMOZA, Luis et al. (2017a): 'Strategic and rare elements in Cretaceous-Cenozoic cobalt-rich ferromanganese crusts from seamounts in the Canary Island Seamount Province (northeastern tropical Atlantic)', Ore Geology Reviews Ore Geol. Rev., vol. 87, pp.41-61 (http://dx.doi.org/10.1016/i.oregeorev.2016.10.005).

MARINO, Egidio; BLASCO, Iker; BLANCO, Lorena; GONZÁLEZ, F. Javier; SOMOZA, Luís y MEDIALDEA, Teresa (2017b): 'Llega la era de la minería submarina', Tierra y Tecnología no 49 (DOI http://dx.doi.org/10.21028/em.2017.05.12).

MARTÍN Y PÉREZ DE NANCLARES, José (2016): "Plataforma continental ampliada al oeste de las Islas Canarias: presentación española ante la comisión de límites de la plataforma continental", Revista Española de Derecho Internacional Vol. 68, no 1, pp. 219-226 (http://dx.doi.org/10.17103/redi.68.1.2016.). 
MARTíN RUIZ, Juan Francisco (2005): 'Los espacios marítimos y el problema de su delimitación en la posición geopolítica del Archipiélago canario', Scripta Nova: Revista electrónica de geografía y ciencias sociales, no 9, pp. 181-204 (http://dx.doi.org/10.1344/sn2005.9.896).

NEVES COELHO, Paulo (2017): 'A delimitação dos espaços marítimos de Portugal após a aprovação da extensão da plataforma continental', en GARCÍA PÉREZ, Rafael; NEVES COELHO, Paulo y FERREIRA RODRIGUES, Teresa (coords): $A$ extensão das plataformas continentais: Portugal $e$ Espanha, perspectivas e realidades.Porto,Fronteira do Caos, pp.85-105.

ORIHUELA CALATAYUD, Esperanza (1989): España y la delimitación de sus espacios marítimos. Murcia, Universidad de Murcia.

ORIHUELA CALATAYUD, Esperanza (2011): 'La delimitación de los espacios marinos en los Archipiélagos de Estado. Reflexiones a la luz de la ley 44/2010, de 30de diciembre, de aguas canarias' Revista Electrónica de Estudios Internacionales, № 21 (https://dialnet.unirioja.es/servlet/articulo?codigo=3826884 ).

ORIHUELA CALATAYUD, Esperanza (2014): 'La delimitación de los espacios marinos en España: perspectivas futuras', en MARTíN Y PÉREZ DE NANCLARES, José (dir.): España y la práctica del Derecho Internacional. Madrid, Escuela Diplomática, pp.121-141, (www.exteriores.gob.es/Portal/es/Ministerio/EscuelaDiplomatica/Documents/Coleccion ED 20 web.pdf).

PONTE IGLESIAS, Ma Teresa (2018): Escenario y contexto de la seguridad marítima en el horizonte 2050: minería marina y seguridad ambiental. Madrid, IEEE, 2018 (documento de investigación 20/2018) (http://www.ieee.es/Galerias/fichero/docs investig/2018/DIEEEINV202018SeguridadMaritima.pdf).

SOMOZA, Luis y GONZÁLEZ, Francisco Javier (2011): 'Minería submarina: Se inicia la explotación de los fondos oceánicos', Enseñanza de las Ciencias de la Tierra, vol.19 nำ, pp.115-118.

SOMOZA, Luis; VÁZQUEZ, Juan Tomás; MEDIALDEA, Teresa; PALOMINO, Desirée; GONZÁLEZ, Francisco Javier; FERNÁNDEZ-SALAS, Luis Miguel y LEÓN, Ricardo (2015): '¿Una Atlántida canaria? Descubiertas las 'abuelas submarinas' de las Islas Canarias', Enseñanza de las Ciencias de la Tierra, vol.23 nำ, pp.129-130.

TASSIN, Virginie J. M (2013) : Les défis de l'extension du plateau continental : la consécration d'un nouveau rapport de l'Etat à son territoire. Paris, A. Pedone.

TORREJÓN RODRÍGUEZ, Juan Domingo (2014): La Unión Europea y la cuestión del Sáhara occidental: la posición del Parlamento Europeo. Madrid, Reus.

ZAKARIA ABOUDDAHAB, Mohammed; LOUKILI, Miloud y REIFELD, Helmut (dirs.) (2018): Le Droit de la Mer: enjeux et perspectives pour le Maroc. Rabat, Konrad-Adenauer-Stiftung (https://www.kas.de/c/document library/get file?uuid=3466dba0-14f0-9f51-f00e-

103a0538ce5b\&groupld=252038).

\section{DOCUMENTACIÓN}

COMISIÓN DE LÍMITES DE LA PLATAFORMA CONTINENTAL (2008a): Reglamento de la Comisión de Límites de la Plataforma Continental (CLCS/40/Rev.1) Nueva York, 17.4.2008 (https://undocs.org/es/CLCS/40/Rev.1)[consulta: 9 de enero de 2019]

COMISIÓN DE LÍMITES DE LA PLATAFORMA CONTINENTAL (2008b): Decisión sobre el volumen de trabajo de la CLPC (SPLOS/183), Nueva York, 20.6.2008 https://undocs.org/es/SPLOS/183 [consulta: 14 de enero de 2019]

COMISIÓN DE LÍMITES DE LA PLATAFORMA CONTINENTAL (2009): Exposición del Presidente de la Comisión de Límites de la Plataforma Continental sobre la labor de la Comisión (CLCS/62), Nueva York, 20.4.2009. (https://documents-ddsny.un.org/doc/UNDOC/GEN/N09/307/61/PDF/N0930761.pdf?OpenElement)[consulta: 9 de enero de 2019]

COMISIÓN DE LÍMITES DE LA PLATAFORMA CONTINENTAL (2015): Progresos en la labor de la Comisión de Límites de la Plataforma Continental, 1 de octubre de 2015 (CLCS/90), pp.15-16 
(https://documents-dds-

ny.un.org/doc/UNDOC/GEN/N15/297/42/PDF/N1529742.pdf?OpenElement)[consulta: 9 de enero de 2019]

CORELL, Hans (2002): Letter dated 29 January 2002 from the Under-Secretary-General for Legal Affairs, the Legal Counsel, addressed to the President of the Security Council $(A / 2002 / 161)$, Naciones Unidas (12.2.2002) (http://www.arso.org/Olaeng.pdf)

Convención de Naciones Unidas sobre el Derecho del Mar (CONVEMAR), de 10 de diciembre de 1982 (BOE de 14 de febrero de 1997) (www.un.org/depts/los/convention agreements/texts/unclos/convemar es.pdf)

GREENPACE (2013): Deep Seabed Mining. An urgent wake-up call to protect our oceans (www.greenpeace.org/international/Global/international/publications/oceans/2013/Deep-

Seabed-Mining.pdf)

INSTITUTO ESPAÑOL DE OCEANOGRAFÍA (2011): Informe Científico-Técnico de la Campaña Oceanográfica DRAGO 0511. Ampliación de la Plataforma Continental de España al Oeste de las Islas Canarias, Madrid, Instituto Español de Oceanografía, (www.repositorio.ieo.es/eieo/bitstream/handle/.../Informe\%20DRAGO0511.pdf)

INSTITUTO GEOLÓGICO Y MINERO DE ESPAÑA (2016): Expedición internacional JC142, con participación de organismos científicos de España, Reino Unido y Brasil, (octubre - diciembre 2016), nota de prensa 19.10 .2016 (www.igme.es/SalaPrensa/NotasPrensa/2016/10/NOTA\%20DE\%20PRENSA\%20EXPEDICI\%C3\%93N \%2OINTERNACIONAL\%20JC142.pdf).

INSTITUTO HIDROGRÁFICO DE LA MARINA (2013): Memoria del Instituto Hidrográfico de la Marina. Año 2012, Madrid, Ministerio de Defensa (https://publicaciones.defensa.gob.es/media/downloadable/files/links/P/D/PDF430.pdf).

Ley 44/2010, de 30 de diciembre, de aguas canarias (BOE del 31.12.2010)(www.boe.es/buscar/pdf/2010/BOE-A-2010-20140-consolidado.pdf)

NACIONES UNIDAS (2006): Resolución aprobada por la Asamblea General el 8 de diciembre de 2006 sobre pesca sostenible (61/105), N. York, Asamblea General (www.un.org/es/comun/docs/?symbol=A/RES/61/105)

NACIONES UNIDAS (2009): Resolución aprobada por la Asamblea General el 4 de diciembre de 2009sobre pesca sostenible (64/72), N. York, Asamblea General(www.un.org/es/comun/docs/?symbol=A/RES/64/72)

NACIONES UNIDAS (2018): Informe del Comité Especial encargado de Examinar la Situación con respecto a la Aplicación de la Declaración sobre la Concesión de la Independencia a los Países y Pueblos Coloniales correspondiente a 2018 (A/73/23), N. York, Asamblea General (https://digitallibrary.un.org/record/1642023/files/A 73 23-ES.pdf)

NEW YORK CITY BAR ASSOCIATION (2011): Report on legal issues involved in the Western Sahara dispute: use of natural resources, N. York, disponible en https://www.nycbar.org/pdf/report/uploads/20072089ReportonLegallssuesInvolvedintheWestern SaharaDispute.pdf

PARLAMENTO EUROPEO (2018): Resolución del Parlamento Europeo, de 16 de enero de 2018, sobre la gobernanza internacional de los océanos: una agenda para el futuro de nuestros océanos en el contexto de los Objetivos de Desarrollo Sostenible para 2030 (2017/2055(INI)) (http://www.europarl.europa.eu/sides/getDoc.do?type=TA\&reference=P8-TA-2018-

0004\&language $=\mathrm{ES} \&$ ring $=\mathrm{A} 8-2017-0399$ ) 
PORTUGUESE REPUBLIC (2009): Continental Shelf of Portugal. Executive Summary. Estrutura de Missão para a Extensão da Plataforma Continental (EMEPC) (www.un.org/depts/los/clcs new/submissions files/prt44 09/prt2009executivesummary.pdf). REINO DE ESPAÑA (2006): Límites de la Plataforma Continental de conformidad con el Artículo 76, párrafo 8 de la Convención de Naciones Unidas sobre el Derecho del Mar 1982 con respecto al área del Mar Céltico y el Golfo de Vizcaya. Parte 1 Resumen (www.un.org/depts/los/clcs new/submissions files/frgbires06/presentacion conjunta resumen espanol.pdf).

REINO DE ESPAÑA (2009): Presentación ante la Comisión de Límites de la Plataforma Continental (Presentación parcial relativa a los límites de la Plataforma Continental de España en el área de Galicia, de conformidad con el artículo 76 y el anexo II de la Convención de las Naciones Unidas sobre el Derecho del Mar). Parte 1 Resumen Ejecutivo (http://www.un.org/Depts/los/clcs new/submissions files/esp47 09/esp 2009 summary esp.pd f).

REINO DE ESPAÑA (2014): Presentación parcial de datos e información sobre los límites de la Plataforma Continental de España al Oeste de las Islas Canarias. Parte I Resumen Ejecutivo. (www.un.org/depts/los/clcs new/submissions files/esp77 14/esp 2014 es.pdf)

RÉPUBLIQUE ARABE SAHRAOUIE DÉMOCRATIQUE (2005): Oil \& Gas Licence Offering 2005, Londres, 17.5.2005 (http://www.sadroilandgas.com/pdfs/Oil_GasLicenceOffering17_5_05.pdf).

RÉPUBLIQUE ARABE SAHRAOUIE DÉMOCRATIQUE (2009): Loin ${ }^{\circ}$ 03/2009 du 21 Janvier 2009établissant les zones maritimes de la République Arabe Sahraouie Démocratique. (https://www.wsrw.org/files/dated/2009-05-15/zee maritime rasd.pdf).

Respuesta del Gobierno a la pregunta escrita planteada por la diputada del Grupo Ciudadanos Dña. Melisa Rodríguez Hernández (184/11404), Madrid, 13 de junio de 2017 (www.congreso.es/l12p/e3/e 0038927 n 000.pdf).

ROYAUME DU MAROC (2015): Rapport d'informations sur le Plateau Continental. Atlantique du Royaume du Maroc au-delà des 200. Milles Marins (http://www.un.org/Depts/los/clcs new/submissions files/preliminary/Mor2015 preliminaryinfo. pdf).

ROYAUME DU MAROC (2017a): Projet de loi 37-17 modifiant et complétant le Dahir portant loi 173-211 du 26 moharrem 1393 (2 mars 1973) fixant la limite des eaux territoriales (www.legalflashdoc.com/ws/ged/public/dVPcuHWhUydBAT8C).

ROYAUME DU MAROC (2017b): Conseil de gouvernement du jeudi 6 juillet 2017, Rabat, Ministère de laCulture et de la Communication (www.maroc.ma/fr/actualites/conseil-de-gouvernement-dujeudi-6-juillet-2017).

Tratado entre el Reino de España y la República Portuguesa por el que se establece la línea de cierre de las desembocaduras de los ríos Miño y Guadiana y se delimitan los tramos internacionales de ambos ríos, hecho en Vila Real el 30 de mayo de 2017. BOE núm. 189, de 6 de agosto de 2018 (https://www.boe.es/boe/dias/2018/08/06/pdfs/BOE-A-2018-11228.pdf).

UNIÓN EUROPEA (2018): Sentencia del Tribunal de Justicia (Gran Sala) de 27 de febrero de 2018 (http://curia.europa.eu/juris/document/document.jsf?text=\&docid=199683\&doclang=ES).

\section{NOTAS VERBALES}

- Nota Verbal no NV/187/09 de la Misión Permanente de Marruecos ante las Naciones Unidas, de 16 de mayo de 2009 (http://www.un.org/Depts/los/clcs new/submissions files/esp47 09/mor re esp2009.pd f)

- Nota verbal ONU/2009/134de la Misión Permanente de Portugal ante las Naciones Unidas $\begin{array}{lllll}\text { de } & 28 & \text { de } & \text { mayo } & \end{array}$ (http://www.un.org/Depts/los/clcs new/submissions files/esp47 09/prt re esp2009.pdf) 
- Nota Verbal n 353AV/otde la Misión Permanente de España ante las Naciones Unidas, de 28 de mayo 2009 (http://www.un.org/Depts/los/clcs new/submissions files/prt44 09/esp re prt2009.pdf)

- Nota Verbal no NV/ATL/N/ 114/2015 de la Misión Permanente de Marruecos ante las Naciones Unidas, de 10 de marzo de 2015 (http://www.un.org/Depts/los/clcs new/submissions files/esp77 14/mor re esp77.pdf)

- Nota Verbal no $076 \mathrm{MP} / \mathrm{bcm}$ de la Misión Permanente de España ante las Naciones Unidas, $\begin{array}{lllll}\text { de } 22 & \text { de } & \text { abril } & \end{array}$ (http://www.un.org/Depts/los/clcs new/submissions files/esp77 14/prt remar esp77 s pa.pdf)

- Nota Verbal no NV/ATL/N/ 325/2015 de la Misión Permanente de Marruecos ante las Naciones Unidas, de 29 de julio de 2015 (http://www.un.org/Depts/los/clcs new/submissions files/prt44 09/mar re prt2015.pdf)

\section{NOTICIAS DE PRENSA}

$A B C$ (2017a): 'Ocho países se disputan el tesoro minero hallado en aguas de Canarias', $A B C$ (17.4.2017) (https://www.abc.es/sociedad/abci-ocho-paises-disputan-tesoro-minero-halladoaguas-canarias-201704172218 noticia.html).

ABC (2017b): 'Qué es el telurio de Canarias y cómo se podrá sacar del agua', ABC (18.4.2017) (www.abc.es/espana/canarias/abci-telurio-canarias-y-como-saldra-agua-

201704180249 noticia.html).

ABC (2017c): 'Marruecos contrata para su nueva frontera con Canarias al mismo asesor de Londres con Malvinas', ABC (16.7.2017) (www.abc.es/espana/canarias/abci-marruecos-contrata-paranueva-frontera-canarias-mismo-asesor-londres-malvinas-201707161400 noticia.html).

H24info (2017) : 'Le royaume aurait choisi Lindsay Parson pour le conseiller sur le dossier de la délimitation des frontières maritimes du Sahara', H24info (20.7. 2017)

(www.h24info.ma/actu/voici-lexpert-engage-maroc-delimiter-eaux-territoriales-sahara/).

REVISTA INGENIERÍA NAVAL (2018): 'El Parlamento Europeo pide una moratoria para la minería submarina', Revista ingeniería naval, №. 967, 2018 (https://sectormaritimo.es/moratoria-mineriasubmarina).

THE GUARDIAN (2017): 'Is deep sea mining vital for a greener future - even if it destroys ecosystems?', The Guardian (4.6.2017) (www.theguardian.com/environment/2017/jun/04/isdeep-sea-mining-vital-for-greener-future-even-if-it-means-destroying-precious-ecosystems). 